\title{
Chemical pancreatectomy treats chronic pancreatitis while preserving endocrine function in preclinical models
}

\author{
Mohamed Saleh, ${ }^{1,2}$ Kartikeya Sharma, ${ }^{1}$ Ranjeet Kalsi, ${ }^{1}$ Joseph Fusco, ${ }^{1}$ Anuradha Sehrawat, ${ }^{1}$ Jami L. Saloman, ${ }^{3}$ Ping Guo, ${ }^{4}$ \\ Ting Zhang, ${ }^{1}$ Nada Mohamed, ' Yan Wang, ${ }^{1}$ Krishna Prasadan,' and George K. Gittes' \\ 'Division of Pediatric Surgery, 'Division of Pediatric Endocrinology, UPMC Children's Hospital of Pittsburgh, Pittsburgh, Pennsylvania, USA. ${ }^{3}$ Department of Medicine, Division of Gastroenterology, Hepatology, \\ and Nutrition, Department of Neurobiology, Pittsburgh Center for Pain Research, University of Pittsburgh School of Medicine, Pittsburgh, Pennsylvania, USA. ${ }^{4}$ Department of Clinical Science, Colorado State \\ University, Fort Collins, Colorado, USA.
}

\begin{abstract}
Chronic pancreatitis affects over $\mathbf{2 5 0 , 0 0 0}$ people in the US and millions worldwide. It is associated with chronic debilitating pain, pancreatic exocrine failure, and high risk of pancreatic cancer and usually progresses to diabetes. Treatment options are limited and ineffective. We developed a new potential therapy, wherein a pancreatic ductal infusion of $1 \%-2 \%$ acetic acid in mice and nonhuman primates resulted in a nonregenerative, near-complete ablation of the exocrine pancreas, with complete preservation of the islets. Pancreatic ductal infusion of acetic acid in a mouse model of chronic pancreatitis led to resolution of chronic inflammation and pancreatitis-associated pain. Furthermore, acetic acid-treated animals showed improved glucose tolerance and insulin secretion. The loss of exocrine tissue in this procedure would not typically require further management in patients with chronic pancreatitis because they usually have pancreatic exocrine failure requiring dietary enzyme supplements. Thus, this procedure, which should be readily translatable to humans through an endoscopic retrograde cholangiopancreatography (ERCP), may offer a potential innovative nonsurgical therapy for chronic pancreatitis that relieves pain and prevents the progression of pancreatic diabetes.
\end{abstract}

\section{Introduction}

Chronic pancreatitis (CP) affects approximately 250,000 people in the US and millions worldwide (1-4), and the incidence is increasing with the increase in alcohol abuse (5). Also, cystic fibrosis (CF), the most common inherited disease in White people in the US, is characterized by pancreatic inflammation leading to islet loss and diabetes mellitus (6). Patients with CP suffer from chronic pain that compromises quality of life (7), have exocrine pancreatic insufficiency, and develop a brittle form of diabetes (8). Additionally, patients with CP have a roughly 13 -fold increased risk of pancreatic ductal adenocarcinoma (9), a common and highly lethal form of cancer $(10,11)$. The treatment options for CP are limited, marginally effective, and usually cause endocrine tissue loss (12).

Pancreatic diabetes occurs in approximately $80 \%$ of patients with CP (13). Management of pancreatic diabetes is challenging because, besides loss of insulin-producing $\beta$ cells, there is concomitant loss of the glucagon-producing $\alpha$ cells (presumably because all islet cells are subjected to the inflammatory milieu). Glucagon is a counterregulatory hormone that rescues hypoglycemia. With glucagon deficiency, a slight insulin overdose could cause severe

\section{Related Commentary: https://doi.org/10.1172/JCl146210}

Authorship note: KS and RK contributed equally to this work.

Conflict of interest: The authors have declared that no conflict of interest exists.

Copyright: (5) 2021, American Society for Clinical Investigation.

Submitted: August 13, 2020; Accepted: December 1, 2020; Published: February 1, 2021

Reference information: J Clin Invest. 2021;131(3):e143301.

https://doi.org/10.1172/JCl143301. life-threatening hypoglycemia $(14,15)$. Overall, CP patients consume copious resources and cause a substantial economic burden (16). CF-related diabetes (CFRD) is also a distinct form of pancreatic diabetes associated with increased morbidity and mortality (6). The etiology of CFRD is multifactorial, with the primary etiology being relative insulin insufficiency due to islet loss (6). Approximately $40 \%-50 \%$ of adults with CF develop CFRD, and the incidence is rising (17).

Surgical intervention in CP can entail major surgeries, including partial and total pancreatectomy (8). Total pancreatectomy with islet autotransplantation (TPIAT) has evolved to treat CPassociated pain while preserving some endocrine function, but it is a surgery with high morbidity with variable outcomes, and substantial islet loss occurs during both islet isolation and reinfusion (18). Thus, new therapeutics for CP are needed.

Herein, we demonstrate a potentially novel therapy for $\mathrm{CP}$ through ablation of the exocrine pancreas by delivering a chemical agent, acetic acid (AcA), through the pancreatic duct. Remarkably, the islets of Langerhans remain completely intact. In this study, because of the small size of the animals, a surgical laparotomy to access the pancreatic duct was required. However, pancreatic duct access is routinely and readily achieved in humans via the nonsurgical endoscopic procedure endoscopic retrograde cholangiopancreatography (ERCP). This "chemical pancreatectomy" technique appears to relieve CP-associated pain. Moreover, it may rescue ailing islets by removing the source of injury (inflamed exocrine tissue) and thus potentially prevent the progression to, or even foster rescue from, pancreatic diabetes. This approach could also be beneficial for preventing CFRD if given early in the course of the disease 
before the destruction of islets. The incurred loss of exocrine tissue in this procedure would not typically require further management in CP and CF patients because they usually develop pancreatic exocrine failure requiring dietary enzyme supplements. Finally, near-total exocrine pancreas ablation may well minimize the risk of future pancreatic ductal adenocarcinoma in these patients.

\section{Results}

Chemical pancreatectomy ablates the exocrine pancreas, but spares islets. Eight-week-old outbred (CD1) mice from either sex were divided into 3 groups: AcA-treated, saline-treated, and unoperated (naive). Gross morphology of the pancreas 2 days after AcA infusion showed a markedly abnormal appearance, with tissue whitening, suggesting protein denaturation (Figure 1A). At 2 weeks, the pancreas appeared translucent, suggesting acinar tissue loss, with the islets readily visible (Figure 1A). At 8 weeks, the pancreas appeared fatty, with the islets remaining visible. The gross morphology of the pancreas did not change at 6 months compared with 8 weeks after AcA infusion. Fatty replacement is a welldescribed common phenomenon in the human pancreas that can occur with aging, obesity, CF, pancreatitis, and diabetes (19-22).

Pancreatic histopathology showed acinar cell injury and necrosis 2 days after AcA infusion (Figure 1, B and C). At 2 weeks, there was near-complete loss of the acinar cells, with inflammation and accompanying fibrosis (Figure 1D and Supplemental Figure 1A; supplemental material available online with this article; https:/doi. org/10.1172/JCI143301DS1). At 4 weeks, fat cells started to replace the exocrine pancreas, and this process was complete by 8 weeks (Figure 1D). Pancreatic histology remained unchanged at 6 months (Figure 1D) compared with at 8 weeks after AcA infusion. Two days after AcA infusion, some areas in the pancreas showed apparently preserved acinar cell architecture (Figure 1C); however, IHC showed a marked decrease in amylase staining, but with normal insulin staining (Figure 1E). The loss of amylase immunostaining here may be due to degradation of zymogen enzymes in the injured acinar cells. In line with the IHC findings, at 2 days, a Western blot showed decreased amylase in AcA-infused pancreata compared with that of control groups (Figure 2, A and B), while insulin protein expression was not statistically different among the 3 groups (Figure 2, A and C). Two weeks onwards after AcA infusion, immunostaining showed no amylase, with normal insulin staining (Figure 1E). Time course of inflammatory changes in the exocrine pancreas following AcA infusion showed the exocrine pancreas infiltrated with lymphocytes, macrophages, and neutrophils at 2 days, but there was no infiltration into the islets (Supplemental Figure 1A). The inflammation peaked at 2 weeks, then regressed by 4 weeks, and eventually disappeared by 8 weeks (Supplemental Figure 1A). Also, cytokeratin (Figure 2D) and SOX9 (Supplemental Figure 1B) immunostaining demonstrated increased ducts and duct-like structures at 2 weeks, followed by a decrease at 4 weeks, and a complete absence of pancreatic ducts at 8 weeks after AcA infusion. Those early duct-like structures may represent an aborted attempt at exocrine pancreas regeneration.

Two days after surgery, serum pancreatic enzymes (amylase and lipase) in AcA-treated mice and saline-treated controls were elevated over those of naive mice, suggesting that the AcA and saline infusions similarly caused pressure-induced pancreatitis (Supplemental Figure 1, C and D). One week and 8 weeks after surgery, there was no statistically significant difference in serum pancreatic enzymes among the 3 groups, indicating resolution of the infusion-induced transient pancreatitis (Supplemental Figure 1, C and D).

Panoramic histology of the whole pancreas 1 year after AcA infusion revealed persistent near-complete loss of the exocrine pancreas with stable fatty replacement and normal-appearing islets (Figure 2E).

Chemical pancreatectomy preserves the integrity of the islets. After AcA infusion, despite near-complete ablation of the acinar cells, the islets appeared normal (Figure 1, D and E). Immunostaining for laminin and collagen 4 demonstrated an intact islet capsule (Supplemental Figure 2A). Immunostaining for the endothelial marker CD31 after AcA infusion showed a normal dense islet vasculature (Figure $3 \mathrm{~A})$. Quantification of the $\mathrm{CD} 31^{+} /$islet area ratio showed no difference between AcA-treated mice and control groups at 6 months after AcA infusion (Figure 3B). Six months after AcA infusion, the whole-mount IHC allowed detailed visualization of an intact islet vasculature (Figure 3C). Islet capillaries are highly specialized, with dense fenestrations in the vicinity of endocrine cells that facilitate rapid glucose sensing and release of hormones (23). Six months after AcA infusion, electron microscopy (EM) showed intact dense fenestrations (Figure 4, A and B). Immunostaining for the neuron marker PGP9.5 revealed that the pancreas remained innervated at serial time points after AcA infusion (Figure 4C). Whole-mount IHC at 6 months after AcA infusion revealed intact nerve endings supplying the islets (Figure 4D). Additionally, although $1 \%$ AcA is sufficient to destroy acinar cells, the number of neurons in the dorsal root ganglion (DRG) at the T12 level (which normally contains the highest concentration of pancreas afferents) was normal in AcA-treated mice, suggesting that AcA is not grossly cytotoxic to sensory neurons (Supplemental Figure 2, B and C).

Mode of cell death and acinar cell susceptibility to cell injury after AcA treatment. Immunostaining for cleaved caspase-3 showed no evidence of apoptosis (Supplemental Figure 3A). The absence of caspase- 3 in the setting of inflammation (Figure 1 and Supplemental Figure 1) suggests necrosis as the mechanism of AcA-induced acinar cell death. EM of pancreas 2 days after AcA infusion confirmed signs of cell injury and necrosis (Figure 5, A-D). To determine whether AcA-induced cell death was explicitly due to acidity, we infused citric acid $(6 \mathrm{mM})$, which has a $\mathrm{pH}$ equivalent to $1 \%$ AcA (174 mM, pH of approximately 2.75 ) into the pancreatic duct. The pancreatic histology was normal 2 weeks after citric acid infusion, indicating that AcA's toxicity is not merely due to low $\mathrm{pH}$ (Supplemental Figure 3B).

We then examined the direct effect of AcA on acinar cell clusters versus islets in vitro. Acini and islets were isolated from naive mice and cultured for 1 hour, then exposed to 1\% AcA for 1 minute or 5 minutes, followed by immediate washing with PBS. Cell viability was assessed by propidium iodide (PI) staining and FACS. Acinar and islet viability were normalized to their respective control acini and islets not exposed to AcA. The islet cells had significantly higher viability compared with acinar cells after exposure to AcA at both 1 minute $(P<0.0001)$ and 5 minutes $(P<0.0001)$, suggesting that acinar cells are more vulnerable to AcA-induced cell death (Figure 5E and Supplemental Figure 3, C and D).

To study the role of islet integrity in their relative resistance to AcA, islets were isolated from naive mice and cultured in cell 
A

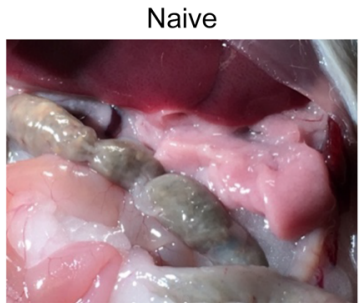

B

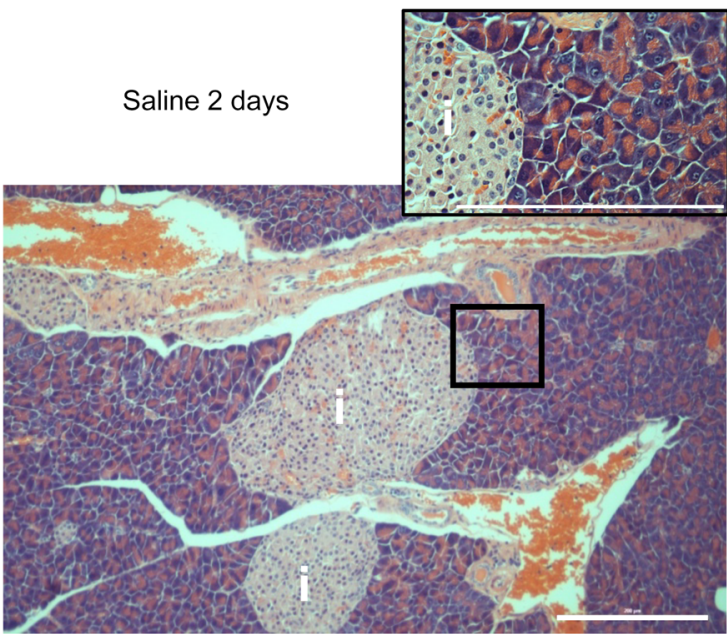

D

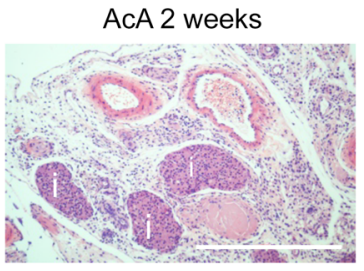

E

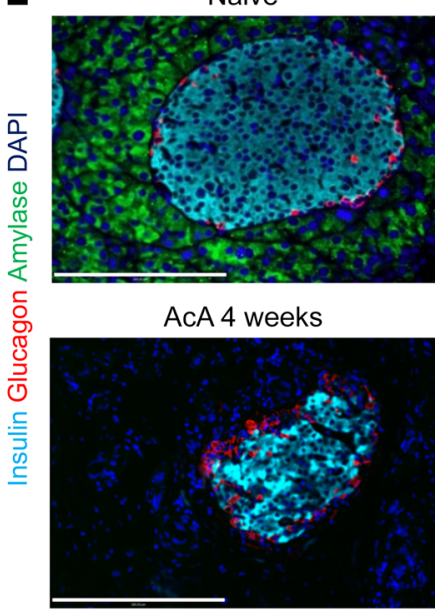

AcA 2 days

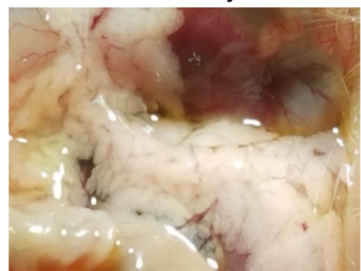

प

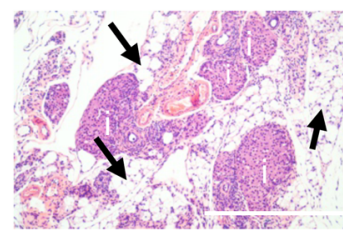

AcA 8 weeks
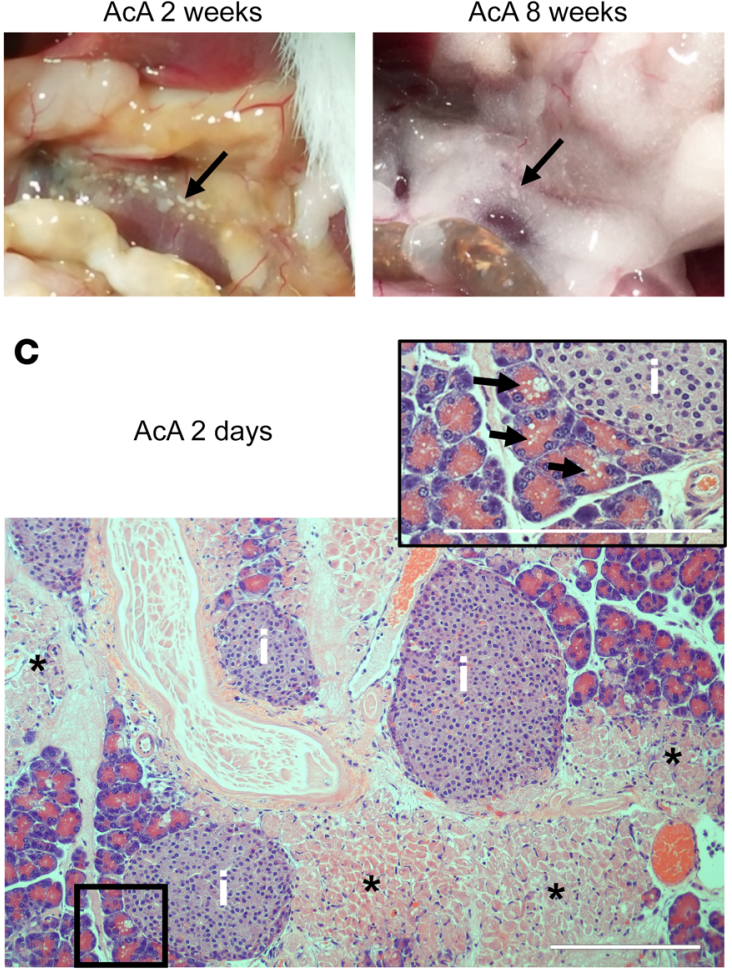

AcA 8 weeks

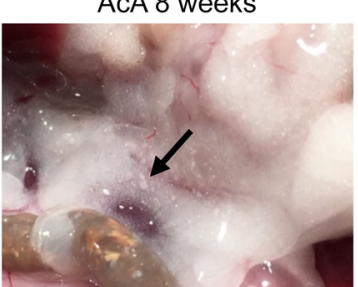

AcA 6 months
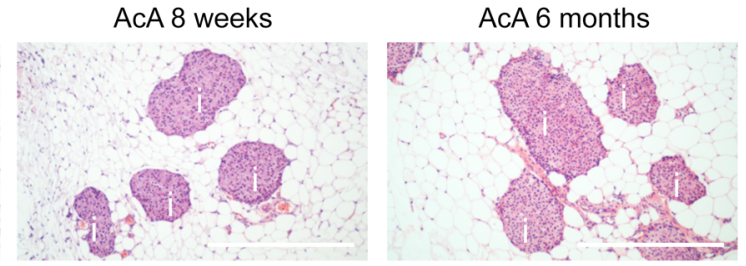

AcA 2 weeks
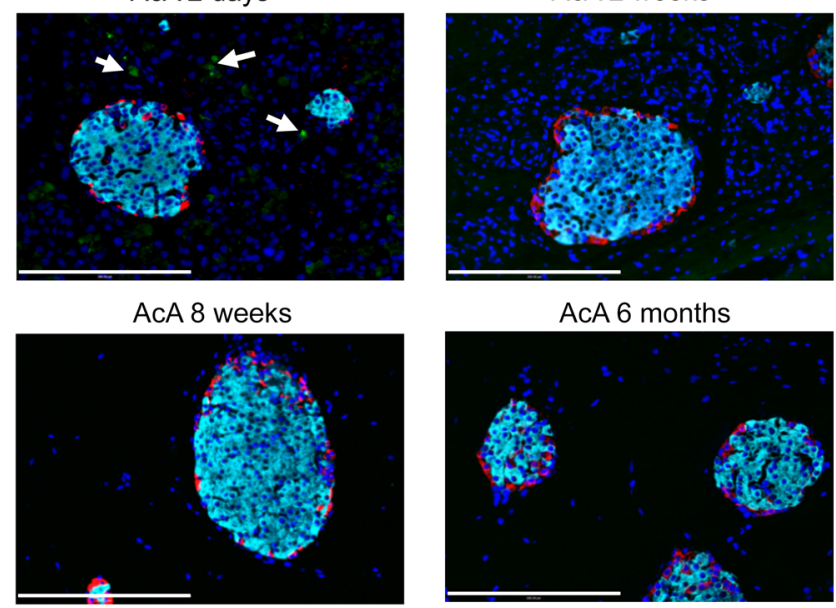

AcA 6 months

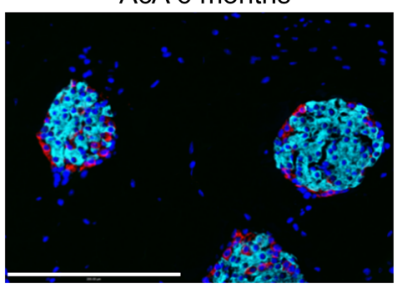

Figure 1. Morphological and histological changes in mouse pancreas following chemical pancreatectomy. (A) After AcA infusion, gross morphology of the pancreas was abnormally white and edematous at 2 days, translucent with visible islets (arrow) at 2 weeks, and replaced by fatty tissue with visible islets (arrow) at 8 weeks. (B and C) Normal pancreas histology 2 days after saline infusion (B). Two days after AcA infusion, there was exocrine tissue necrosis (asterisks) with intact islets (i). Magnification (inset) of the apparently preserved acinar cells revealed cell swelling and cytoplasmic vacuolization (arrows) (C). (D) Histology of the pancreas after AcA infusion. Intact islets are denoted by i. Arrows denote fat cells at 4 weeks. (E) Immunostaining after AcA infusion showed negative amylase staining (arrows denote amylase remnants at 2 days), with normal insulin and glucagon staining. Illustrative histology results from 5 animals per time point are shown. Scale bars: $200 \mu \mathrm{m}$. 
A

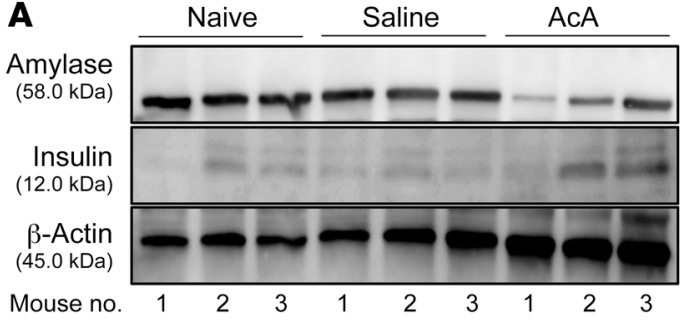

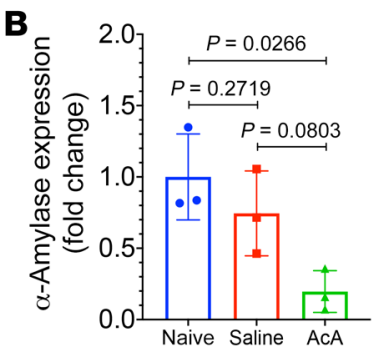

D

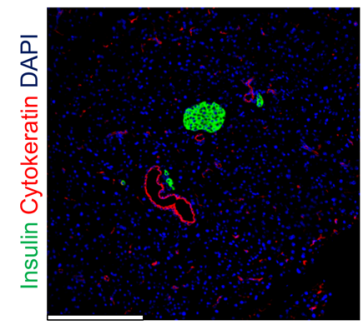

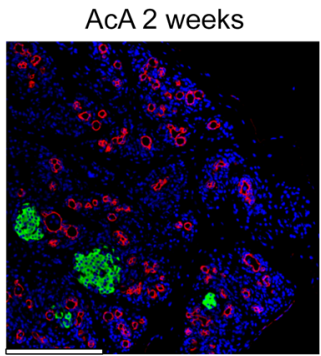
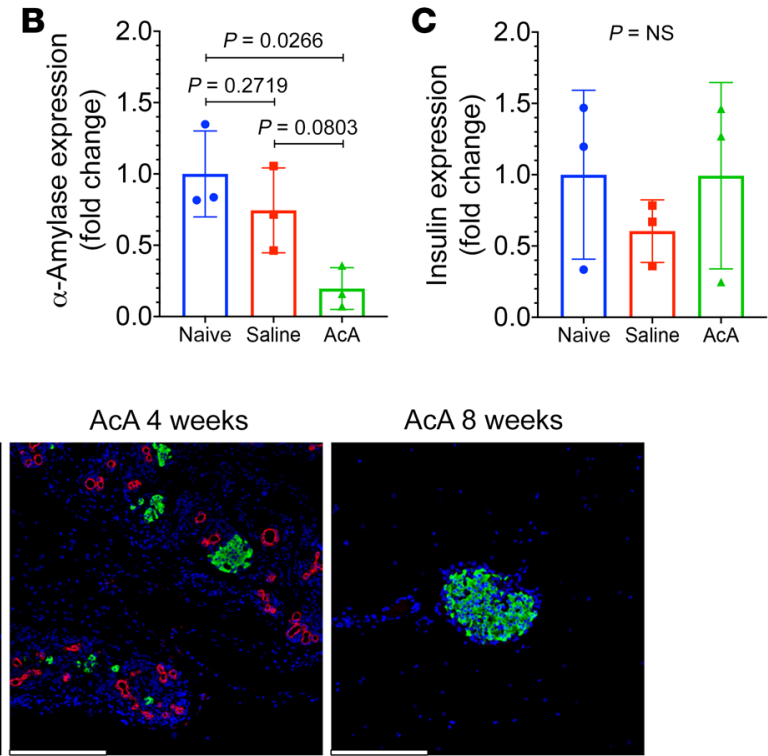

$\mathbf{E}$

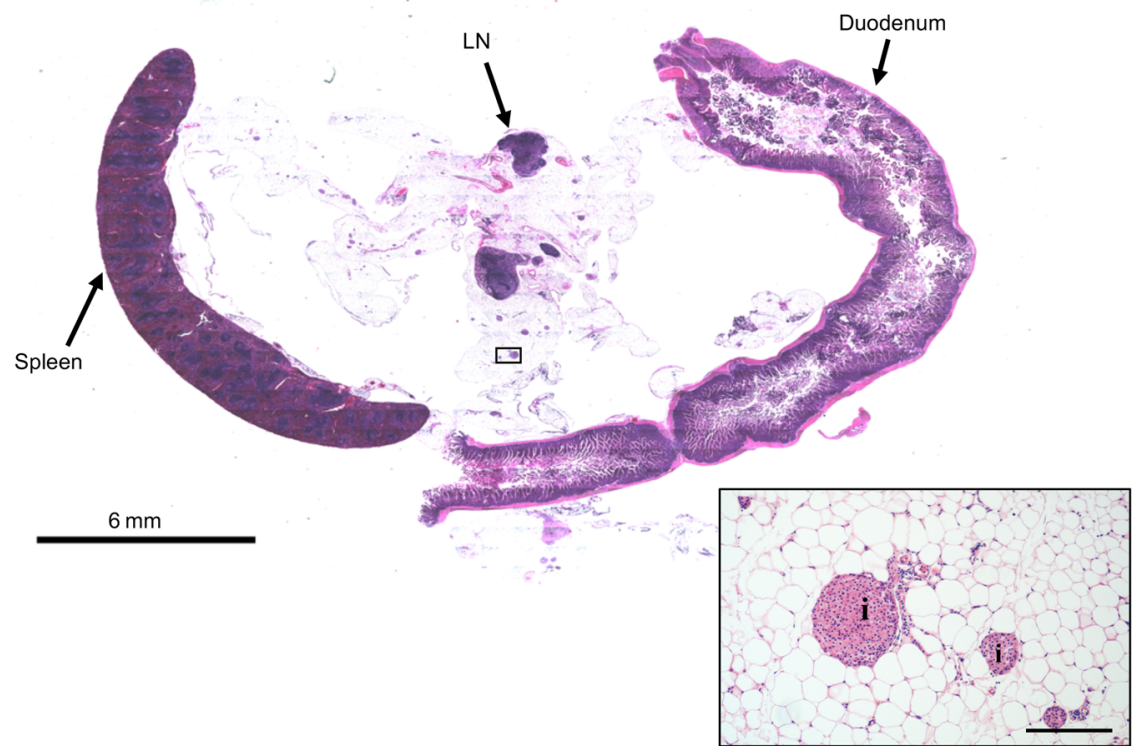

Figure 2. Chemical pancreatectomy causes nonregenerative ablation of exocrine pancreas and spares islets. (A-C) Protein isolated from pancreata, 2 days after surgery (3 mice/group), were loaded on the same gel (A). Western blot protein quantification by densitometry showed decreased amylase protein (B) in the AcA-infused pancreata compared with control groups (1-way ANOVA followed by Holm-Šidák test for multiple comparisons, $F_{2,6}=7.553$; $P=0.0230$ ), with no difference in the insulin protein among the 3 groups (1-way ANOVA, $F_{2,6}=0.5592 ; P=0.5988$ ) (C). $\beta$-Actin was used as a protein loading control for Western blot analysis. (D) Immunostaining for cytokeratin (duct cell marker) in control and AcA-infused pancreata showed the presence of ducts and duct-like structures at 2 weeks and 4 weeks, while at 8 weeks, immunostaining was negative for cytokeratin, suggesting involution of the ducts. (E) One year after AcA infusion, there was persistent loss of exocrine pancreas with intact islets (i). Illustrative histology results from 5 animals per time point are shown. Scale bars: $200 \mu$ m unless otherwise specified. Data are presented as mean \pm SD.

media for 24 hours. A subset of islets was dissociated with trypsin before exposure to $1 \%$ AcA. Another group of intact islets was first exposed to AcA and then dissociated with trypsin for FACS after treatment. Viability of islet cells was normalized to their respective controls not exposed to AcA. Here, the cells from the intact islets exposed to AcA had significantly higher viability than the dissociated islet cells exposed to AcA at 1 minute $(P<0.0001)$, and 5 minutes $(P<0.0001)$. Thus, islet integrity is likely an additional protective factor against AcA-induced cell death during chemical pancreatectomy (Figure 5F and Supplemental Figure 3, E and F).
Chemical pancreatectomy resolves inflammation and ameliorates pain-like behavior in cerulein-induced $C P$. Eight-week-old CD1 mice were divided into 2 groups. Group 1 received i.p. cerulein injections as described in Methods for 8 weeks to induce CP (Figure 6, A and B). Group 2 received i.p. vehicle injections (normal saline). At 8 weeks, each group was split into 2 subgroups; one underwent AcA pancreatic ductal infusion, and the other underwent a normal saline infusion. Thus, 4 experimental subgroups were created: vehicle+saline, vehicle + AcA, cerulein+saline, and cerulein+AcA. 
A

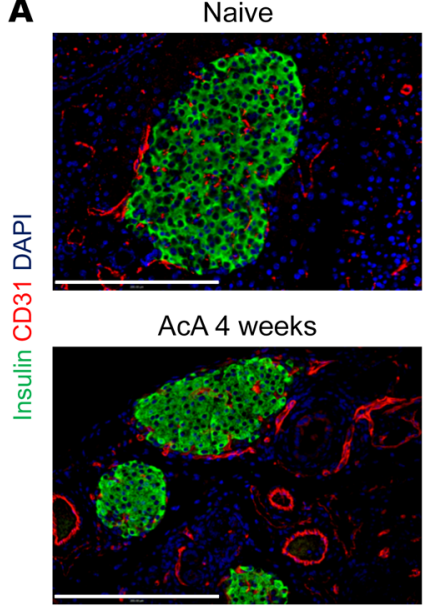

B
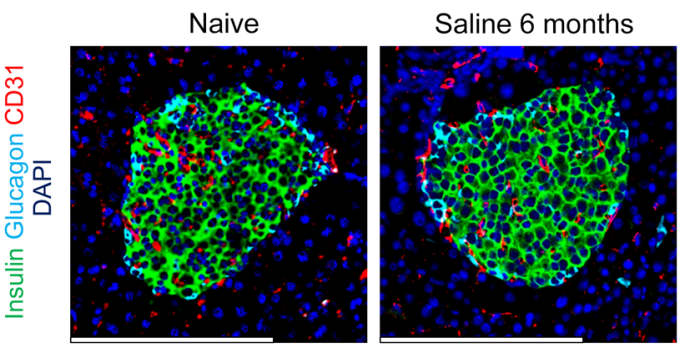

AcA 2 days

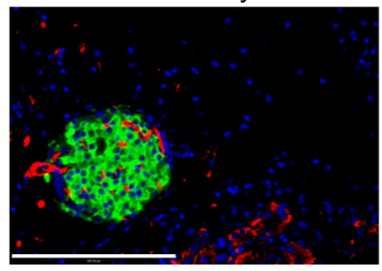

AcA 8 weeks

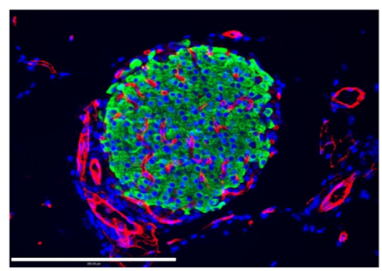

?

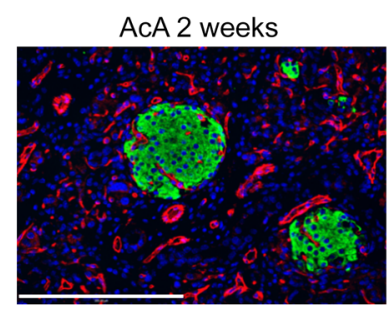

AcA 6 months

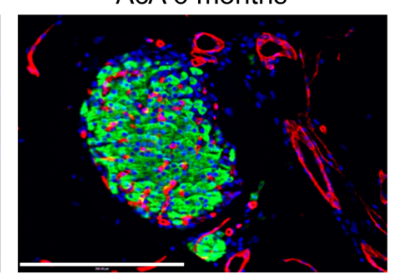

C
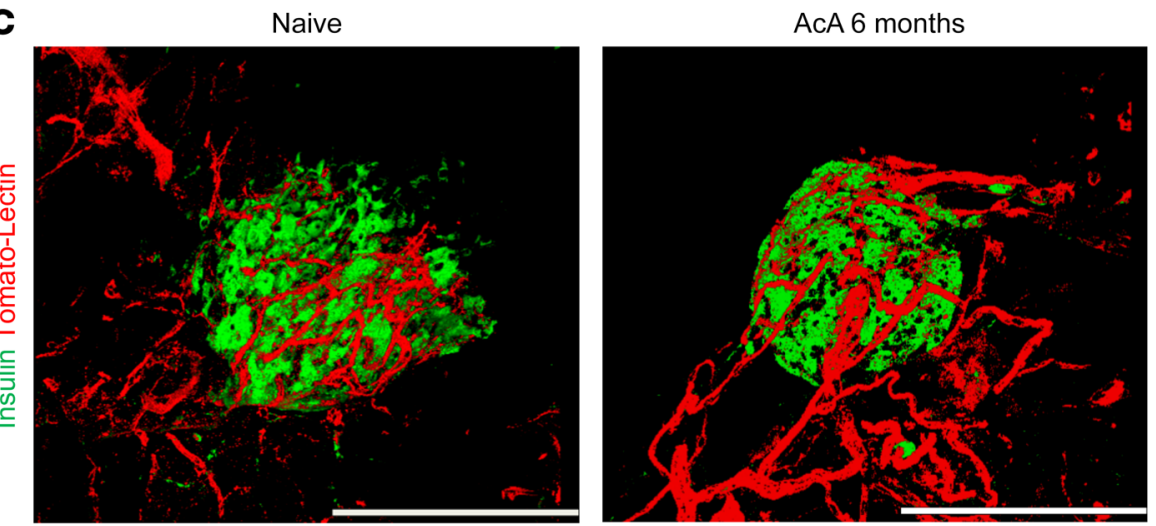

Figure 3. Chemical pancreatectomy preserves the integrity of islet vasculature. (A) Immunostaining for CD31 and insulin showed an intact microvasculature of the islets in AcA-treated mice at all time points. (B) Representative images for CD31 immunostaining of the islets in naive, saline-treated, and AcA-treated mice at 6 months after infusion (left panel). There was no significant difference in the quantification of islet microvasculature among the 3 groups (right panel). One-way ANOVA, $F_{2,9}=0.5013 ; P=0.6217 . n=4$ mice per group, 12 islets per mouse. (C) Whole-mount immunostaining for endothelial cells (Tomato-lectin) and insulin showed intact microvasculature of islets at 6 months after AcA infusion compared with that of naive mice. Illustrative histology results from 5 animals per time point are shown. Scale bars: $200 \mu \mathrm{m}$. Data are presented as mean \pm SD.

One week after the mice recovered from surgery, we resumed i.p. injections of cerulein or vehicle for 8 more weeks to prevent the resolution of $\mathrm{CP}$, which occurs after cerulein cessation (24). Following the two 8-week cycles of i.p. injections, histopathology revealed persistence of the inflamed exocrine pancreas in the cerulein+saline group (Figure 6C and Figure 7A), while the cerulein+ AcA group showed near-complete ablation of the acinar cells (Figure $6 \mathrm{D}$ and Figure $7 \mathrm{~A}$ ). Immunostaining for CD3 showed absence of the characteristic $\mathrm{CP}$ lymphocytic infiltration in the cerulein+ AcA group (Figure 7B). Also, the cerulein+AcA group had signifi- cantly lower serum pancreatic enzymes than the cerulein+saline group, and there was no difference in the serum pancreatic enzymes between the cerulein+AcA group and the 2 vehicle subgroups, indicating that AcA treatment normalized the elevated pancreatic enzymes seen in the CP model (Supplemental Figure 4, A and B). In line with the data in the WT mice, AcA pancreatic ductal infusion ablated ducts in cerulein+AcA group, as evidenced by the cytokeratin (Figure 7C) and SOX9 staining (Supplemental Figure 4C).

For pain assessment, normal 8-week-old CD1 mice (without $\mathrm{CP}$ ) were divided into 3 groups (AcA treated, saline treated, and 
A

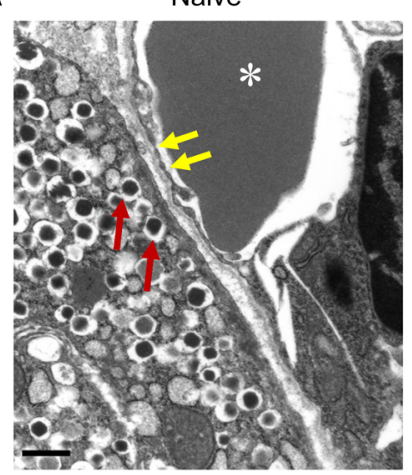

B

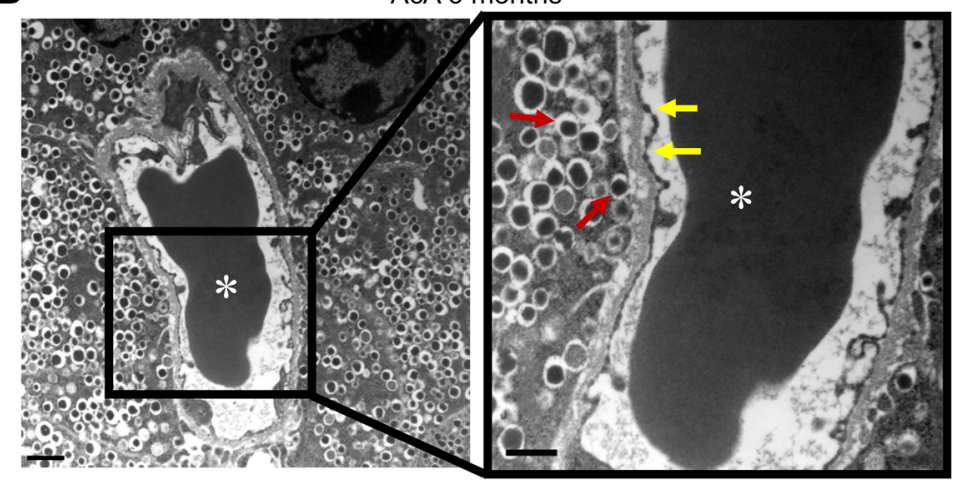

AcA 2 days

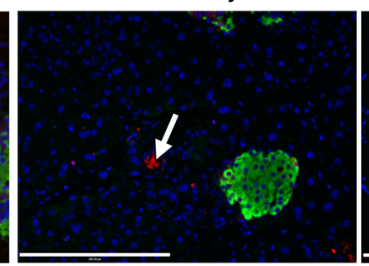

AcA 2 weeks
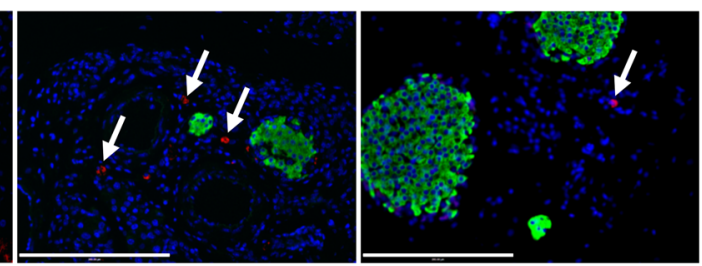

AcA 6 months

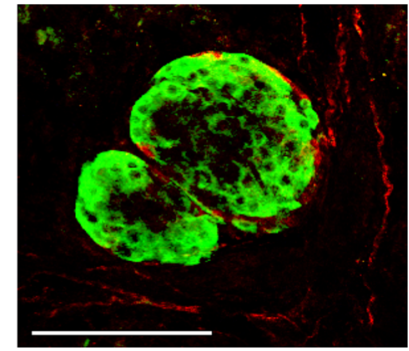

Figure 4. Chemical pancreatectomy preserves the ultrastructure of islet capillaries and innervation. (A and B) EM of the islet capillary-endocrine cell interface in controls (A) and 6 months after AcA infusion (B). Red arrows denote hormone-containing granules of the islet cells. Yellow arrows denote the intact endothelial fenestrations, characteristic of mature islet vessels. Asterisks denote red blood cells in the capillary lumen. Scale bars: $600 \mathrm{~nm}$ (A and B, right panel); $1 \mu \mathrm{m}$ (B, left panel). (C) Immunostaining for PGP9.5 (arrows) and insulin showed intact neurons in the parenchyma of the AcA-treated pancreata at serial time points. (D) Whole-mount immunostaining for neurons (PGP9.5) and insulin in naive pancreas and 6 months after AcA infusion showed apparently intact nerve endings supplying the islets. Illustrative histology results from 5 animals per time point are shown. For the EM, illustrative data from 3 animals are shown. Scale bars: $200 \mu \mathrm{m}$ (C and D).

naive). The abdominal von Frey monofilament assay was performed 8 weeks after surgery by a blinded experimenter. This test is typically abnormal in pancreatitis due to pain and measures the neural response to mechanical stimulation. von Frey testing revealed no differences among the 3 groups, indicating that chemical pancreatectomy alone does not induce hypersensitivity (Supplemental Figure 4D). Next, we determined whether chemical pancreatectomy could reverse cerulein-induced pain (mechanical allodynia). Mice received i.p. cerulein or vehicle for 8 weeks as described. At the 8-week time point, we performed an open-field test. The cerulein-treated mice showed significantly less distance traveled (Supplemental Figure 4E) and rearing duration (Supplemental Figure $4 \mathrm{~F}$ ), confirming the pain-like behavior of the cerulein-induced CP. Using the 4 previously described subgroups, and after the two 8-week cycles of i.p. cerulein, assessment of mechanical sensitivity (von Frey assay) demonstrated, as expected, that the cerulein+saline group exhibited significant mechanical allodynia as compared with the vehicle-treated subgroups (saline and
AcA; Figure 7D). Importantly, AcA infusion significantly abrogated the cerulein-induced mechanical allodynia (Figure 7D). Thoracic DRGs were harvested from a subset of mice in each treatment subgroup. DRGs from the cerulein+saline group exhibited a significant upregulation of CGRP mRNA, a neuropeptide associated with neurogenic inflammation and peripheral sensitization (Figure 7E). Similarly to what occurred with the behavioral changes, AcA treatment significantly reversed the cerulein-induced upregulation in CGRP mRNA levels (Figure 7E).

Chemical pancreatectomy in nonhuman primates. For human translation, we developed a pancreatic ductal infusion technique in nonhuman primates (NHPs) (Supplemental Figure 5, A-D). The NHPs (Cynomolgus macaques) recovered remarkably well from the procedure. There was no significant difference in the NHPs' comprehensive metabolic profile at baseline and 2 days after surgery (Supplemental Table 1), including liver function testing. NHPs were sacrificed 2 days, 8 weeks, and 6 months after AcA infusion. Grossly, at 8 weeks, the NHP pancreas was small with 
A

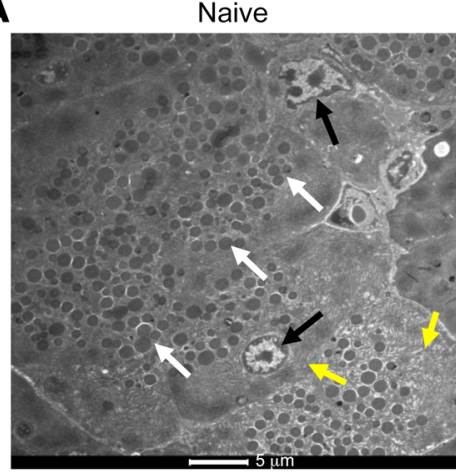

C

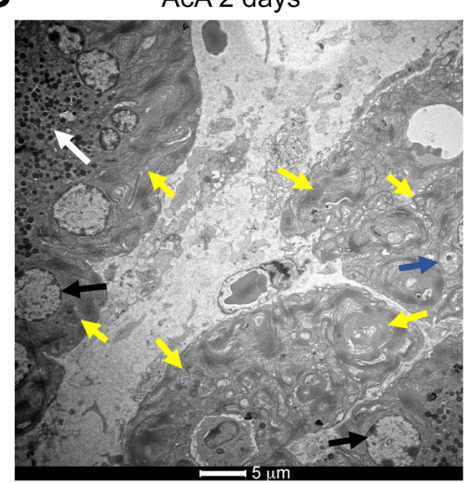

E

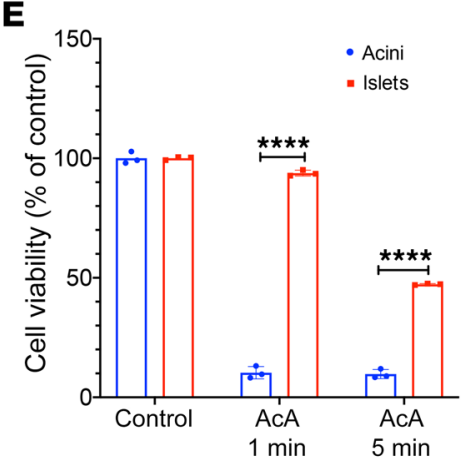

B

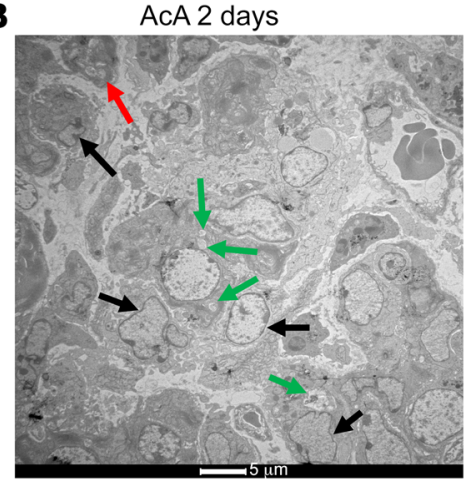

D AcA 2 days (higher magnification)

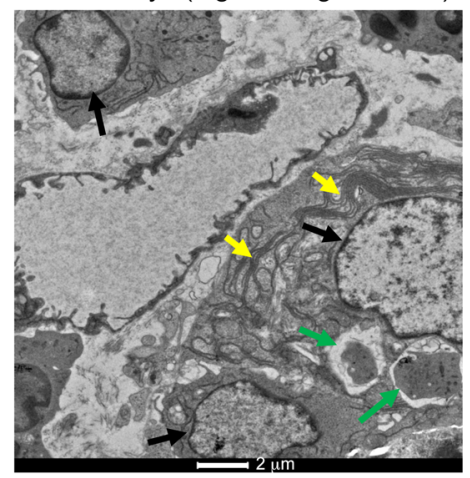

F

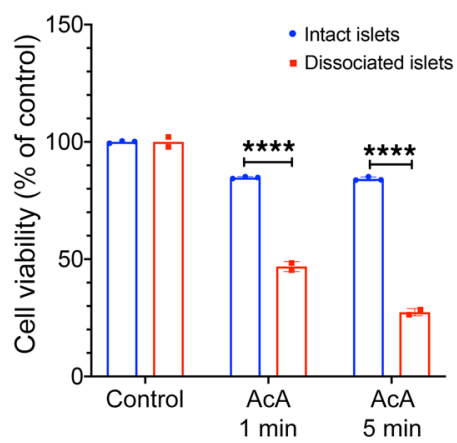

Figure 5. Mode of cell death and acinar cell susceptibility to cell injury after AcA treatment. (A-D) EM images. Naive pancreas shows normal zymogen granules (white arrows), normal nuclei (black arrows), and normal endoplasmic reticulum (yellow arrows) (A). Two days after AcA infusion, pancreata showed abnormal acinar cells with signs of cell injury and necrosis (B-D). In B and D, pleomorphic nuclei (black arrows), mitochondrial swelling (red arrow), disorganized rough endoplasmic reticulum (yellow arrows), and debris-filled vacuoles (green arrows). In C, abnormal appearing zymogen granules (white arrow), pleomorphic nuclei (black arrows), enlarged Golgi apparatus (blue arrow), and disorganized rough endoplasmic reticulum (yellow arrows). $n=3 /$ time-point. Scale bars: $5 \mu \mathrm{m}$ (A-C); $2 \mu \mathrm{m}$ (D). (E) In vitro cell viability assessed by PI staining using flow cytometry comparing acinar cell clusters and isolated islets 1 hour after harvesting. Acinar and islet viability were normalized to their respective control acini and islets not exposed to $1 \%$ AcA. Viability of the islet cells was significantly higher than acinar cells after exposure to AcA at 1 and 5 minutes ( $n=3$ /time point in each group). Two-way repeated-measures ANOVA followed by Holm-Šidák test for multiple comparisons. $\mathrm{F}_{2.8}=832.9 ; P<0.0001$. ${ }^{* * *} P<0.0001$. (F) In vitro cell viability assessed by PI staining using flow cytometry comparing intact islets (dissociated with trypsin after exposure to $1 \% A c A$ ) and dissociated islets (dissociated with trypsin before exposure to AcA) 24 hours after harvesting. Islet cell viability was normalized to their respective control not exposed to AcA. The viability of the intact islet cells was significantly higher than the dissociated islet cells after exposure to AcA at 1 and 5 minutes. $n=3$ /time point in the intact islets group; $n=2$ /time point in the dissociated islets group. Two-way repeated-measures ANOVA followed by Holm-Šidák test for multiple comparisons. $\mathrm{F}_{2,8}=462.2$; $P<0.0001$. ${ }^{* * *} P<0.0001$ loss of normal architecture (Supplemental Figure 5E). Similarly to what occurred in mice, histopathology at 2 days showed acinar cell injury and necrosis, while islets remained intact (Figure 8, A and B). At 8 weeks (Figure 8, C and D) and 6 months (Figure 8, E and $\mathrm{F}$ ), the exocrine pancreas was replaced by fibrous tissue and fat cells. In line with the mouse data, measurement of serum pancreatic enzymes showed a peak at 2 days with return to baseline by 7 days (Figure $8, \mathrm{G}$ and $\mathrm{H}$ ). Immunostaining revealed a marked decline in amylase staining at 2 days and negative amylase staining at 8 weeks after AcA infusion (Figure 9A). After AcA infusion, CD31 and PGP9.5 immunostaining revealed normal islet vasculature (Figure 9B) and intact nerve fibers (Figure 9C). As opposed to what occurred in mice, immunostaining for cytokeratin (Figure 9D) and SOX9 (Supplemental Figure 5F) in NHP showed the presence of ducts and duct-like structures at 8 weeks after AcA infusion; however, ducts were absent at 6 months.

Chemical pancreatectomy improves glucose tolerance and insulin secretion. Two weeks after surgery, both saline-treated and
AcA-treated mice had significantly lower body weight than naive mice (Supplemental Figure 6A); all mice were maintained on an elemental diet/normal chow combination (1:1 ratio). However, 8 weeks after surgery, there were no differences in the body weight among the 3 groups (Supplemental Figure 6B). i.p. glucose tolerance testing (i.p. GTT) at 2 weeks (Supplemental Figure 6, C and D) and 8 weeks (Figure 10, A and B) after surgery revealed a surprising improved glucose tolerance in the AcA-treated mice when compared with control groups. Insulin tolerance testing (ITT) demonstrated no differences in insulin sensitivity among the 3 groups at 2 weeks (Supplemental Figure 6, E and F) and 8 weeks (Figure 10, C and D), indicating that the improved glucose tolerance was not due to increased insulin sensitivity.

An in vivo i.v. glucose-stimulated insulin secretion (GSIS) test was done to allow assessment of early phase insulin secretion. At 8 weeks after surgery, i.v. GSIS (Figure 10, E-H) showed increased insulin secretion in the AcA-treated group compared with that in normal controls, suggesting that loss of the exocrine tissue in 
A

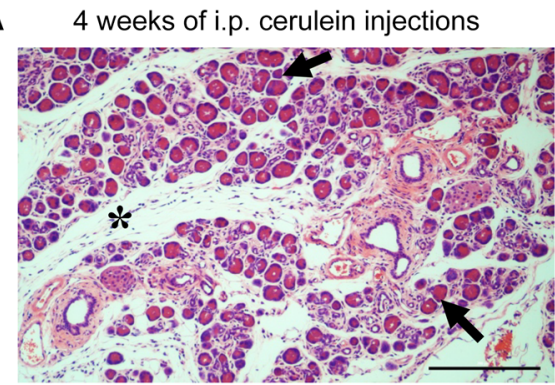

B

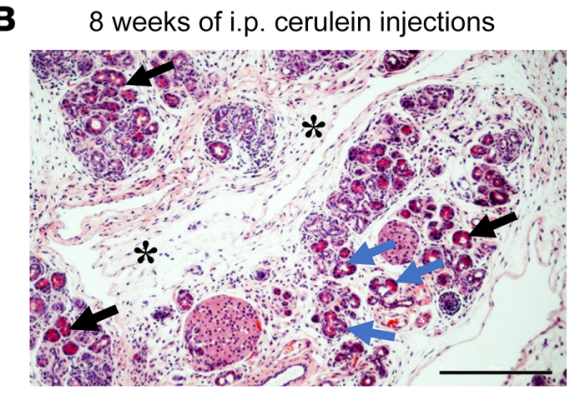

C

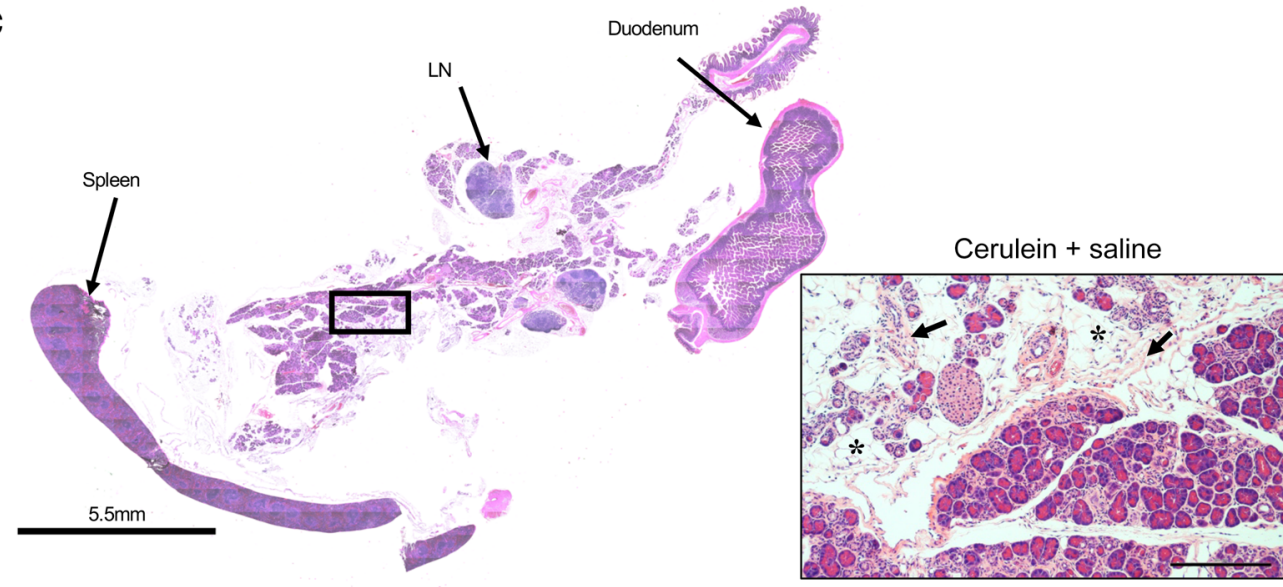

Figure 6. Panoramic view of histology of the pancreas before and after chemical pancreatectomy in cerulein-induced CP. (A and B) Pancreas histology after 4 weeks and 8 weeks of i.p. cerulein showed abnormal acini (black arrows), acinar to ductal metaplasia (blue arrows), and fibrosis (asterisks). (C)Pancreas histology after two 8-week cycles of i.p. injections in the cerulein+saline group showed fibrosis (inset arrows) and fatty replacement (inset asterisks).

(D) Pancreas histology after two 8-week cycles of i.p. injections in the cerulein+AcA group showed near-complete loss of pancreatic parenchyma with intact islets (I). Illustrative histology results from 4 animals per time point are shown. Scale bar: $200 \mu$ m unless otherwise specified.

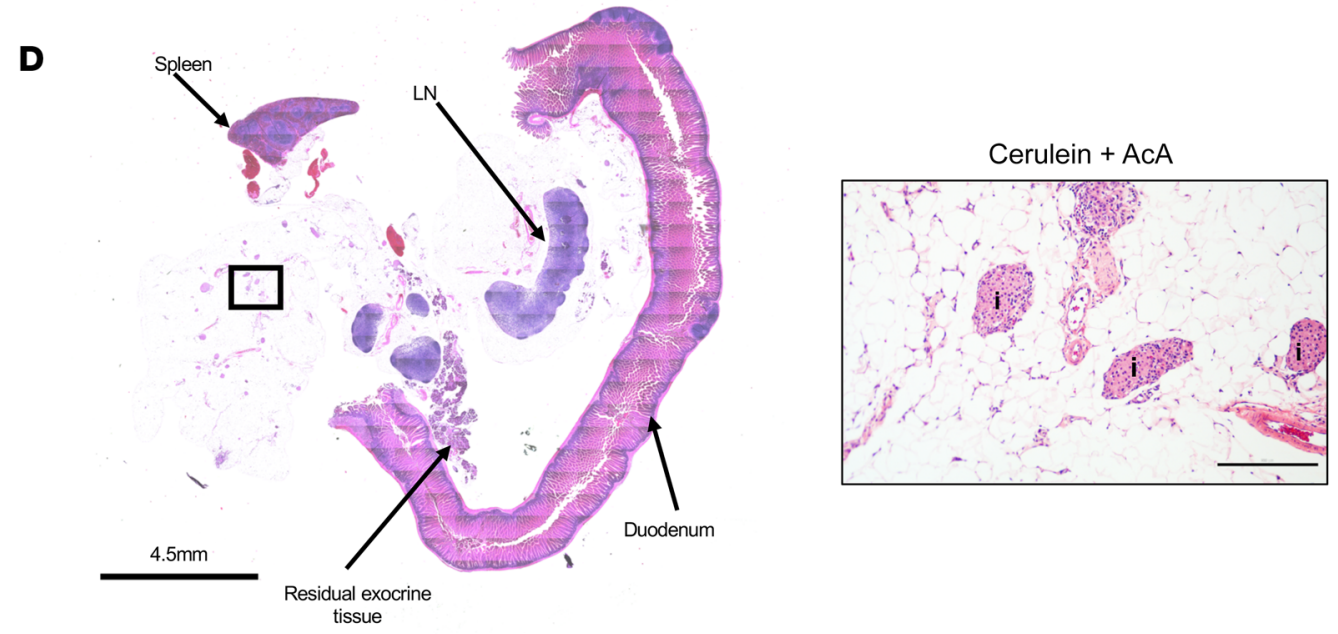

normal mice improves insulin secretion. There was no significant difference in $\beta$ cell mass at 8 weeks among the 3 groups, indicating that chemical pancreatectomy does not cause irreversible loss of $\beta$ cells (Figure 10I), and suggesting that the improvement in glucose tolerance was not due to an increased $\beta$ cell mass. Next, in vitro GSIS of isolated islets from AcA-treated, saline-treated, and naive mice showed no difference in insulin secretion among the 3 groups (Figure 10J), suggesting that the difference seen in the in vivo GSIS is likely secondary to local in vivo anatomical/physiological changes accompanying chemical pancreatectomy.

In line with these data, using the same 4 subgroups described in the CP model experiments, i.p. GTT 1 day after the last cerulein injection showed improved glucose tolerance in AcA-treated subgroups compared with saline-treated subgroups (Figure 10,
$\mathrm{K}-\mathrm{N})$. To confirm the finding that loss of the exocrine pancreas is the main cause of the improved glucose tolerance, we used another mouse model (Ela ${ }^{\text {CreERT2-R26 }}{ }^{\text {DTR }}$ ) that uses the diphtheria toxin receptor (DTR), where diphtheria toxin (DT) quickly ablates acinar cells through apoptosis (25). Two days after the last DT injection, again, the i.p. GTT showed significantly improved glucose tolerance in the Ela ${ }^{\text {CreERT2 }}$ R26 ${ }^{\text {DTR }}$ mice compared with their littermate controls (Supplemental Figure 6, G-I). Additionally, 3 weeks after DT, to allow regeneration of exocrine pancreas (25), there was no difference in the repeat i.p. GTT between the 2 groups (Supplemental Figure 6, J-L), supporting our finding that the acute loss of acinar cells improves glucose tolerance.

In line with the mouse data, 8 weeks after AcA infusion, i.v. GTT in NHPs showed improved glucose tolerance in the 

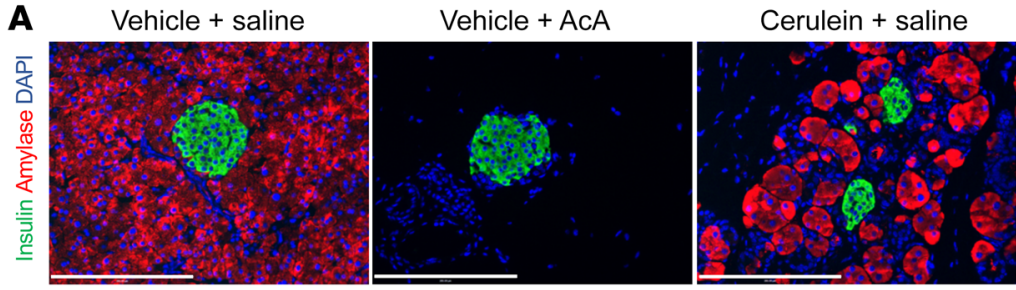

Cerulein $+\mathrm{AcA}$
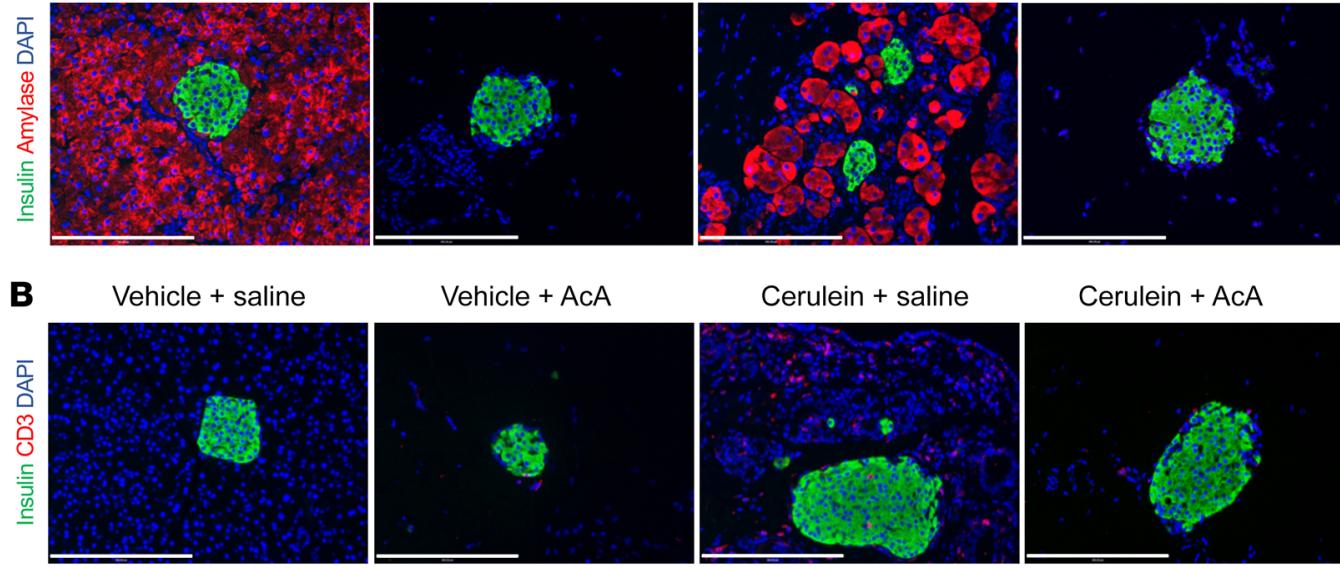

C

Vehicle + saline

Vehicle + AcA

Cerulein + saline

Cerulein + AcA
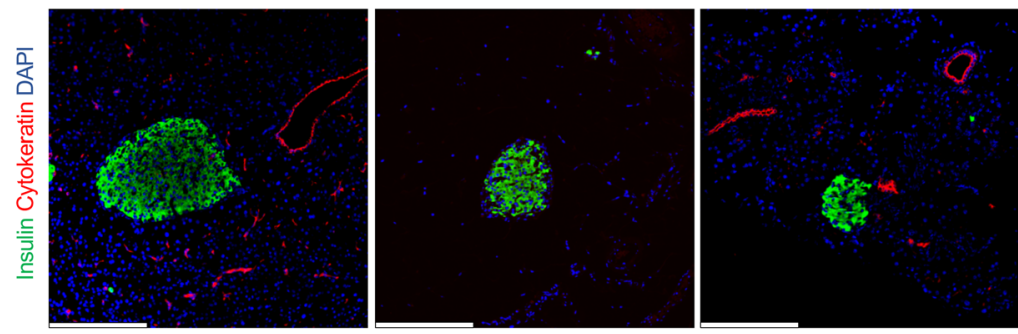

Cerulein + AcA
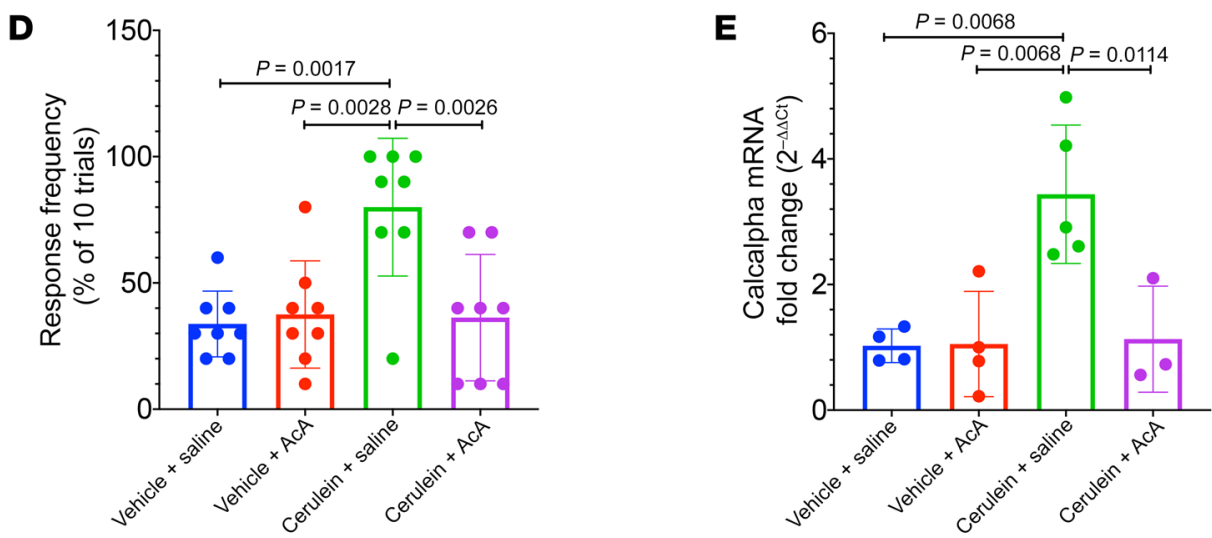

Figure 7. Chemical pancreatectomy ablates exocrine pancreas, resolves inflammation, and ameliorates pain in cerulein-induced CP. (A)Immunostaining for amylase was positive in vehicle+saline and negative in AcA-treated groups while cerulein+saline group showed abnormal patchy amylase staining typical of CP. (B)Immunostaining for CD3 showed presence of lymphocytes only in the cerulein+saline group, indicating chronic inflammation. (C)Immunostaining for cytokeratin showed absence of ducts only in the AcA-treated groups, indicating involution of the ducts. (D)Abdominal von Frey monofilament testing was performed following the two 8-week cycles of i.p. cerulein or vehicle and revealed that cerulein+saline group exhibited significant mechanical allodynia pain as compared with cerulein+AcA group, as well as compared with both vehicle-treated groups, indicating that AcA treatment resolved the pain in cerulein-induced CP. $n=8$ /group. One-way ANOVA followed by Holm-Šidák test for multiple comparisons. $\mathrm{F}_{3,28}=7.884 ; P=0.0006$. (E)Levels of CGRP (calcalpha) mRNA were quantified by RT-PCR from DRGs harvested from the 4 subgroups. In keeping with the in vivo pain assessment, there was a significant upregulation in the cerulein+saline $(n=5)$ group compared with the other 3 groups, cerulein+AcA $(n=3)$, vehicle + saline $(n=4)$, and vehicle + AcA $(n=4)$, indicating that AcA treatment reversed the cerulein-induced upregulation in CGRP mRNA levels. One-way ANOVA followed by Holm-Šidák test for multiple comparisons. $\mathrm{F}_{3,12}=9.015 ; P=0.0021$. Illustrative histology results from 4 animals per time point are shown. Scale bars: $200 \mu \mathrm{m}$. Data are presented as mean \pm SD. Only significant $P$ values are depicted.

AcA-treated NHPs compared with weight- and age-matched controls (Figure 10, O and P, and Supplemental Figure 6M).

\section{Discussion}

$\mathrm{CP}$ - and $\mathrm{CF}$-associated pancreatic inflammation are common problems that can be debilitating and often cause a particularly brittle form of diabetes. Therapeutic options for CP are limited and suboptimal and usually do not reduce the risks of diabetes and pancreatic cancer (26). Here we present a paradigm-shifting nonsurgical "chemical pancreatectomy" as a potential therapy for CP. Remarkably, in mice and NHPs, this procedure led to near-total ablation of the exocrine pancreas, but with complete 

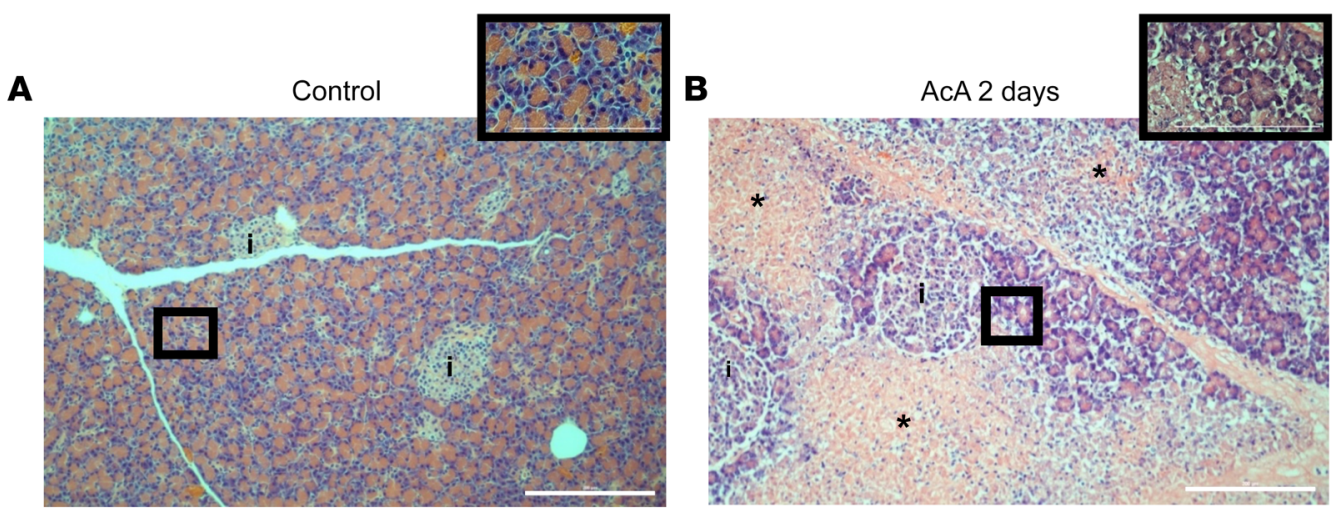

C

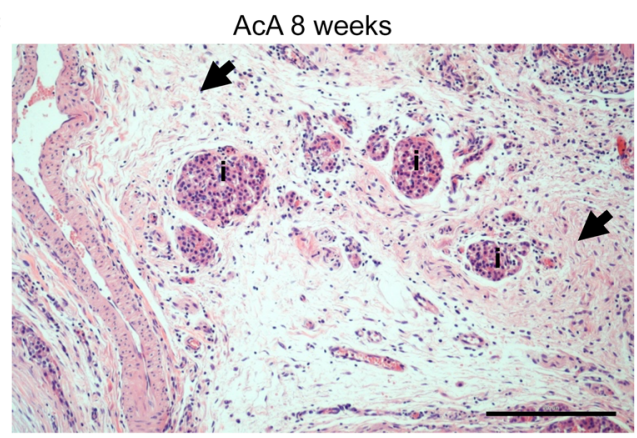

E

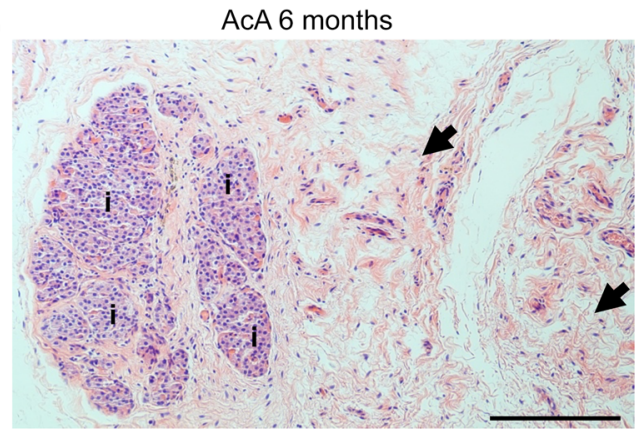

G

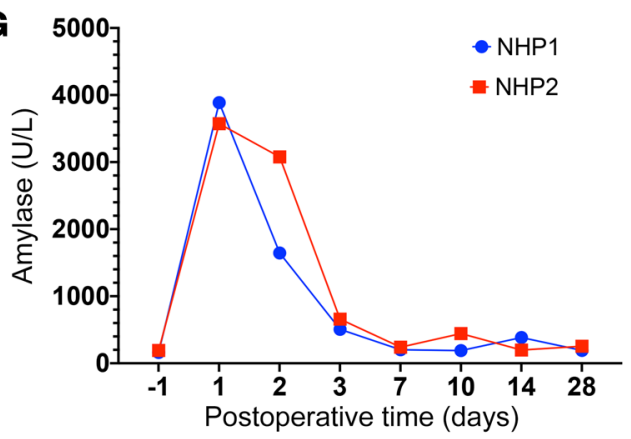

D

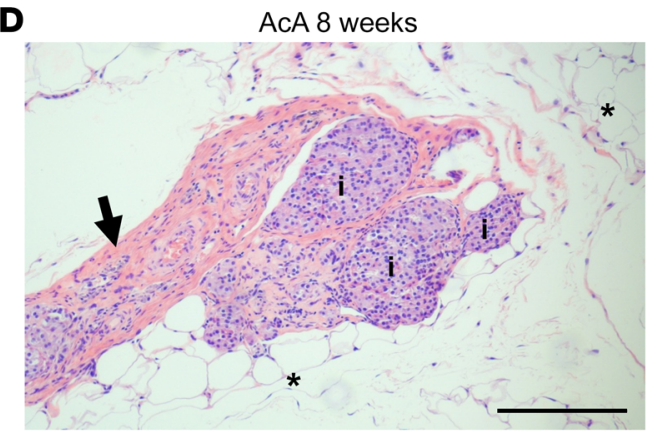

$\mathbf{F}$
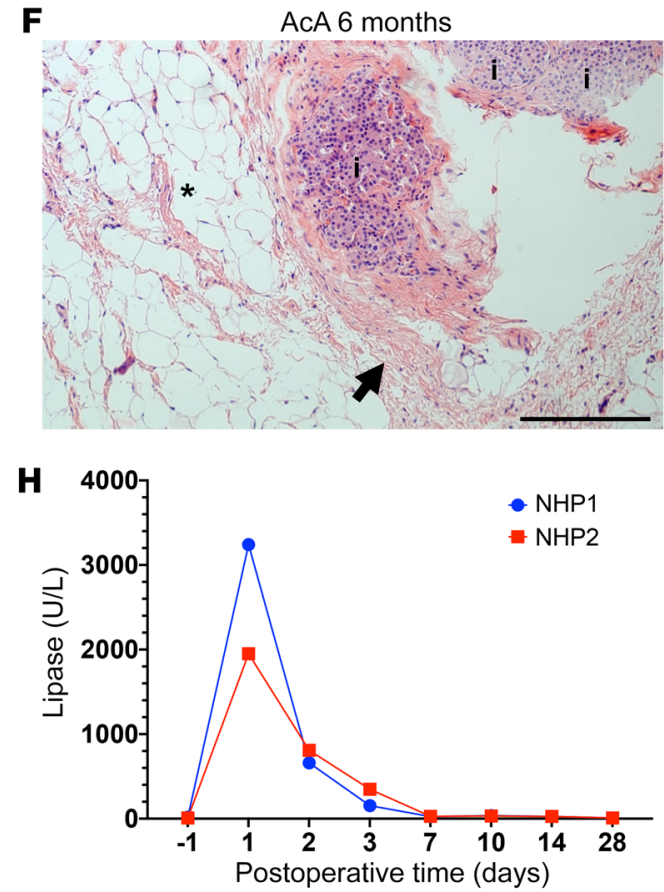

Figure 8. Histological and biochemical changes following chemical pancreatectomy in NHPs. (A) Histology of normal NHP pancreas. i denotes islets. (B) Histology of NHP pancreas 2 days after AcA infusion showed extensive areas of exocrine tissue necrosis (asterisks) with intact islets. Magnification of the exocrine tissue with apparently preserved architecture revealed abnormal acini with acinar cell swelling, indicating cell injury. (C-F) Histology of the pancreas 8 weeks ( $\mathbf{C}$ and D), and 6 months (E and $\mathbf{F}$ ) after AcA infusion showed disappearance of the exocrine tissue with intact islets. The acinar cells are replaced by fibrosis (arrows) and fat cells (asterisks). (G and $\mathbf{H}$ ) Measurement of serum pancreatic enzymes in NHPs; serum amylase (C) and lipase $(\mathbf{H})$ levels returned to preoperative baseline 7 days after surgery. Illustrative results from 2 animals per time point are shown (for 6-month time point, $n$ =1). Scale bars: $200 \mu \mathrm{m}$. preservation of the endocrine cells, and relieved $\mathrm{CP}$-associated pain. Since pancreatic diabetes in both CP and CF is thought to be due to an "innocent bystander" injury to islets from the inflammation, nonsurgical removal of the inflamed exocrine pancreas should theoretically protect the islets indefinitely and possibly ameliorate existing diabetes.

The in vivo infusion of AcA into the pancreatic duct allows direct contact of the AcA with ducts and acinar cells, resulting in widespread cell injury and death. The mechanism of cell death is likely necrosis (Figure 1, Figure 2, and Figure 5), characterized by cell swelling and breakdown of the plasma membrane with the release of intracellular contents and local inflammation $(27,28)$.

Histology at 2 days after AcA infusion revealed several areas of advanced exocrine necrosis. Even though the remaining exocrine areas showed apparently preserved tissue architecture, the acinar cells were swollen with vacuolated cytoplasm and distorted architecture, indicating significant cell injury (Figure 1 and Figure 8). Also, amylase immunostaining at 2 days markedly decreased and was absent by 2 weeks. Other studies reported preservation of tissue architecture for 7 days after exposure to an injurious stimulus 
A

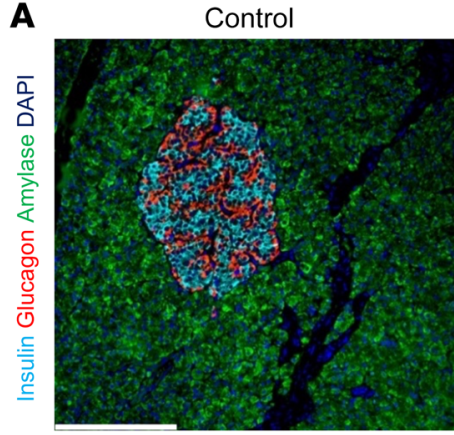

B

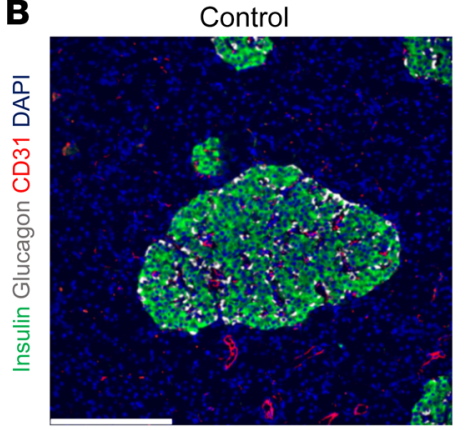

C

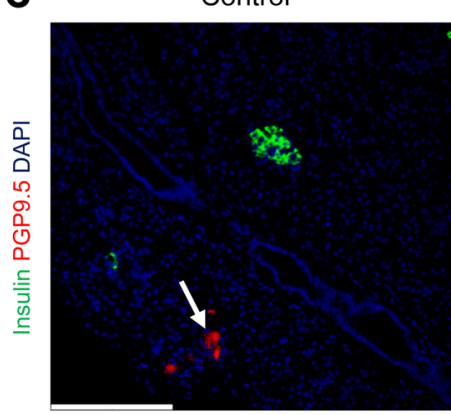

AcA 2 days

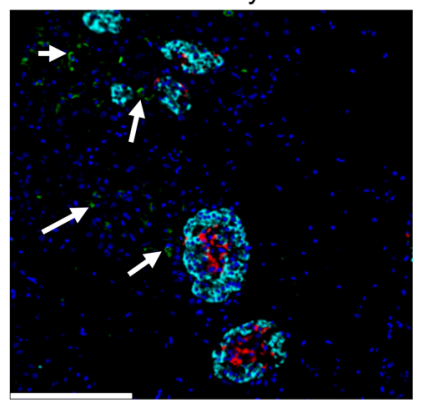

AcA 2 days

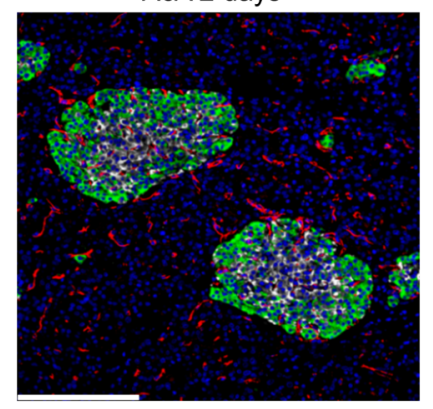

AcA 2 days

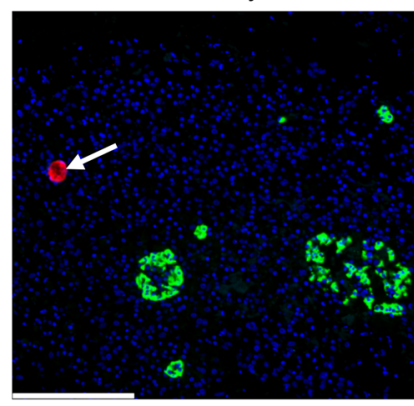

AcA 8 weeks

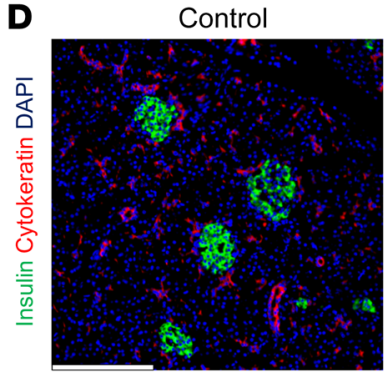

AcA 2 days

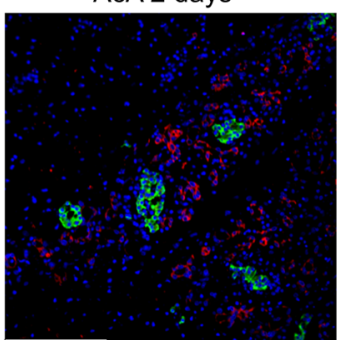

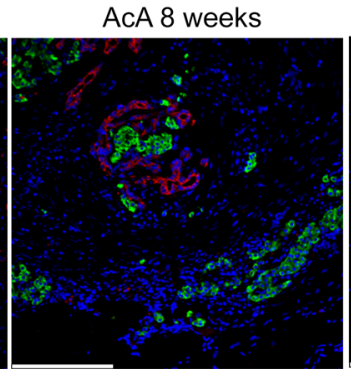

AcA 8 weeks

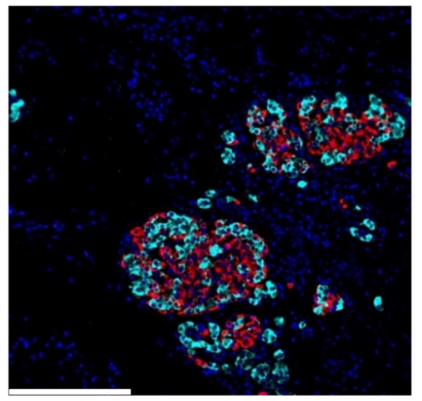

AcA 8 weeks

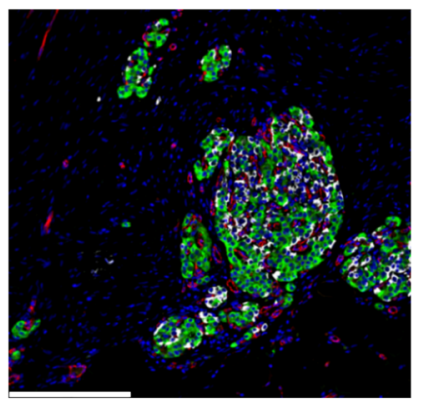

AcA 8 weeks

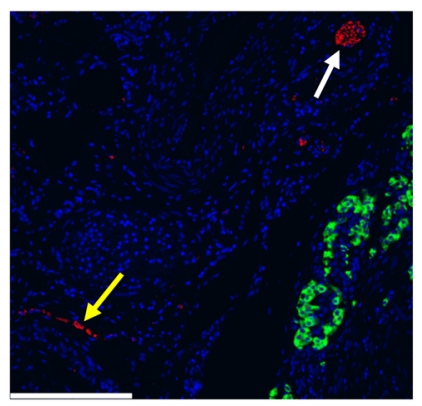

AcA 6 months

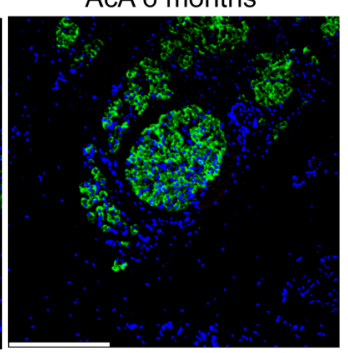

Figure 9. Chemical pancreatectomy ablates exocrine pancreas, and preserves pancreas innervation and islet vasculature in NHPs. (A) Immunostaining for insulin, glucagon, and amylase in NHP's pancreas 2 days after AcA infusion; there was marked decrease in amylase staining (arrows denote amylase remnants) with normal insulin and glucagon staining. At 8 weeks, there was no amylase staining, with normal insulin and glucagon staining. (B)Immunostaining for CD31 showed intact microvasculature of islets at 2 days and 8 weeks after AcA infusion. (C)Immunostaining for PCP9.5 showed intact neurons (white arrows) in the NHP pancreas at 2 days and 8 weeks after AcA infusion. Yellow arrow denotes intact nerve fibers 8 weeks after AcA infusion. (D) Immunostaining for cytokeratin showed presence of ducts at 2 days and 8 weeks after AcA infusion. However, at 6 months, the cytokeratin immunostaining was negative indicating absence of ducts. Illustrative results from 2 animals per time point are shown (for 6-month time point, $n=1$ ). Scale bars: $200 \mu \mathrm{m}$.

(28). By EM, the acinar cells showed alterations in the plasma and organelle membranes, indicating cell injury and necrosis, except for the nuclear envelope, which can initially remain intact (ref. 29 and Figure 5). One year after AcA infusion, the loss of exocrine pancreas was persistent, indicating a lack of regeneration (Figure 2 ). As duct cells can contribute to regeneration of the pancreas (25,
30), the complete absence of pancreatic ducts in this model (Figure 2 and 9, and Supplemental Figures 1 and 5) may explain the inability of the exocrine pancreas to regenerate. Also, the absence of ducts to drain enzymes may further contribute to the death of any acinar cells that might survive the initial AcA-induced injury. Inadequate drainage of pancreatic secretions is well known 

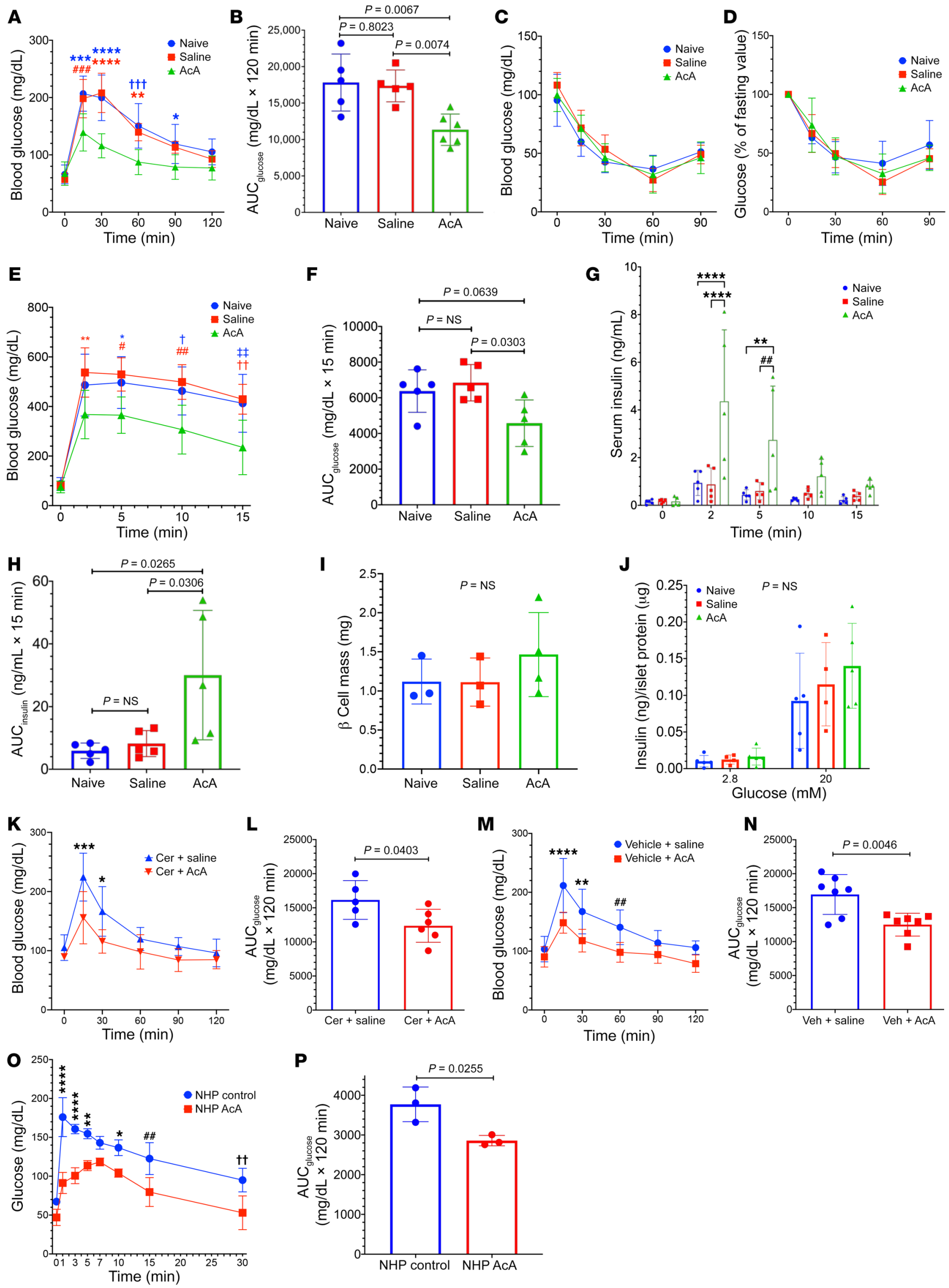
Figure 10. Chemical pancreatectomy improves glucose tolerance and insulin secretion. (A and B) i.p. CTT 8 weeks after surgery (A) comparing AcA group $(n=6)$ and controls ( $n=5 /$ group). Two-way repeated-measures ANOVA, $\mathrm{F}_{10.65}=7.231 ; P<0.0001$. For $\mathbf{A},{ }^{*} P=0.035 ;{ }^{* *} P=0.0026 ;{ }^{* *} P$

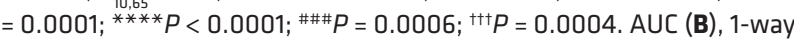
ANOVA, $F_{2,13}=9.234 ; P=0.0032$. (C and D) ITT at 8 weeks (C). (D) Percentage change in glucose levels compared with fasting glucose. $n=4$ naive; 5 saline, and 5 AcA. Two-way repeated-measures ANOVA, $F_{8,44}=1.130$; $P=0.3626$. (E and F) i.v. GTT (E) $n=5$ per group. Two-way repeatedmeasures ANOVA, $\mathrm{F}_{8.48}=3.241 ; P=0.005$. For $\mathbf{E},{ }^{*} P=0.0367 ;{ }^{* *} P=0.0082$; ${ }^{\#} P=0.0108 ;{ }^{\# \#} P=0.0023 ;{ }^{\dagger} P=0.0112 ;{ }^{\dagger \dagger} P=0.0021 ;{ }^{\ddagger \ddagger} P=0.0035$. AUC (F), 1-way ANOVA, $F_{2,12}=5.167 ; P=0.0241$. (G and $\mathbf{H}$ ) In vivo CSIS (G). $n=5$ /group. Two-way repeated-measures ANOVA, $\mathrm{F}_{8.88}=5.267 ; P<0.0001$. For $\mathbf{G}$, ${ }^{* *} P$

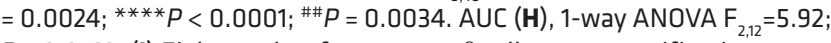
$P=0.0163$. (I) Eight weeks after surgery, $\beta$ cell mass quantification. $n=4$ AcA, 3 naive, and 3 saline. One-way ANOVA, $F_{2,7}=0.8376 ; P=0.4719$. (J) In vitro GSIS. $n=5$ naive, 4 saline, and 5 AcA. Two-way repeated-measures ANOVA, $\mathrm{F}_{2,11}=0.5903 ; P=0.5708$. $(\mathrm{K}-\mathrm{N})$ i.p. GTT comparing the cerulein+ $\operatorname{AcA}$ group $(n=6)$ and cerulein+saline group $(n=5)(K)$. Two-way repeated-measures ANOVA, $\mathrm{F}_{5,45}=4.141 ; P=0.0035$. For $\mathbf{K},{ }^{*} P=0.0150$; ${ }^{* *} P=$ 0.0006. AUC (L), unpaired $t$ test, $\mathrm{t}_{9}=2.394 ; P=0.0403$. i.p. GTT comparing vehicle+AcA and vehicle+saline groups. $n=7 /$ group (M). Two-way repeatedmeasures ANOVA, $\mathrm{F}_{5,60}=5.1 ; P=0.0006$. For $\mathbf{M},{ }^{* *} P=0.0016$; ${ }^{* * *} P<$ $0.0001 ; \# P=0.0068$. AUC (N), unpaired $t$ test, $\mathrm{t}_{12}=3.475 ; P=0.0046$. $(\mathbf{O}$ and $\mathbf{P}$ ) i.v. GTT 8 weeks after surgery in NHPs. $n=3 /$ group. Two-way repeated-measures ANOVA, $\mathrm{F}_{728}=5 ; P=0.0008$. For $\mathbf{O},{ }^{*} P=0.0152 ;{ }^{*} P=$ $0.0026 ;{ }^{\# \#} P=0.0024 ;{ }^{\dagger+} P=0.0025,{ }^{* * *} P<0.0001$ ). AUC (P), unpaired $t$ test, $\mathrm{t}_{4}=3.472 ; P=0.0255$. Data are presented as mean $\pm \mathrm{SD}$. Holm-Šidák test was used for multiple comparisons.

to cause acinar cell death, as seen in the pancreatic duct ligation model (31). In vivo, in order to reach the islets, the AcA must diffuse across the gap junctions between acinar cells, the acinar basement membrane, the interstitial space, and finally, the protective islet capsule (32). Also, during this journey, the concentration of AcA likely becomes progressively more diluted, well below the starting concentration, by interstitial fluid and by lymphatic and vascular clearance from the peri-islet region. Furthermore, in vitro, islets were substantially more resistant to AcA toxicity than acini. Collectively, these factors could explain why the islets were spared. We also found that in vitro, intact islets were even more resistant than dissociated islet cells, perhaps due to the multiple layers of cells in the intact islet (Figure 5).

Interestingly, the loss of the exocrine pancreas improved glucose tolerance and enhanced insulin secretion in vivo (Figure 10, and Supplemental Figure 6). However, in vitro GSIS was unaffected. Islet histology, innervation, and vasculature (Figures 3, 4, and 9) remained intact after AcA treatment; therefore, loss of the exocrine pancreas is likely the main reason for improved $\beta$ cell function. This conclusion is further supported by the ElaCreERT2 $-R 26^{\text {DTR }}$ mouse model data (Supplemental Figure 6).

The rapid rise in serum pancreatic enzymes early after the AcA or saline infusion is likely related to infusion-induced pressure and acute acinar cell damage. The normalization of serum enzymes at 1 week indicates no ongoing pancreatic inflammation caused by the AcA. Similarly, we found that the animals did not appear to be in pain from the infusion after recovering from the surgery. Interestingly, the serum pancreatic enzymes after AcA treatment did not fall below normal levels despite the near absence of acinar tissue. This observation may be attributable to other tissue sourc- es of serum amylase and lipase and/or small residual remnants of pancreatic acinar tissue. It has been shown that removal of the pancreas and salivary glands in rodents did not cause a significant decrease in blood amylase levels (33). Also, significant levels of amylase activity remain in the serum for an indefinite time after pancreatectomy in dogs and humans $(34,35)$. Additionally, serum amylase levels were found to be associated with various physiological changes, such as impaired hepatic function, and are not merely a marker of exocrine pancreatic function $(36,37)$.

We have frequently observed small remnants of acinar tissue in proximity to the duodenum, which we suspect results from these areas having separate small ducts draining directly into the duodenum and thus not in communication with the main ductal system that receives the infusion. This type of drainage has been described for heterotopic pancreas in humans elsewhere along the gastrointestinal tract (38).

The resolution of the CP-associated pain is likely due to the resolution of the inflammation, suggesting that the pain is secondary to damaged perineurium as well as direct activation and sensitization of sensory nerve fibers by factors in the inflammatory milieu $(39,40)$. CP-associated pain may evolve to central sensitization, where removal of the pancreatic source of the pain may not remove the pain, and such may be the case in a subset of patients $(41,42)$. However, surgical total pancreatectomy can typically improve CP-associated pain (43). Thus, chemical pancreatectomy will likely be beneficial for improving pain in CP.

In NHPs, the texture and anatomy of the pancreas are quite different from those in the mouse (2\% AcA was more effective in NHPs). We saw many similarities between the histological changes in NHPs and in mice early on after the AcA treatment. However, at the 8-week and 6-month time points, instead of seeing a complete fatty replacement of the acinar cells that occurs in mice, in NHPs, we saw fatty replacement plus fibrosis in the nonendocrine portion of the pancreas. This difference may be due to a faster pace of pathological changes in mice compared with primates and differences in the healing process between the 2 species. Also, the islets of Langerhans, islet vasculature, and pancreatic innervation were preserved. These findings make the translation of chemical pancreatectomy to humans possible, a potential dramatic advancement in the management of patients with CP.

Although chemical pancreatectomy has shown favorable outcomes in animal models, the effect of the chemical pancreatectomy procedure on a preexisting premalignant lesion, if present, in patients with $\mathrm{CP}$ is not known at this point. This will require further studies in order to translate this procedure to humans successfully.

Another potential limitation of this study is that abnormal pancreatic duct architecture in patients with CP might lead to a nonuniform diffusion of AcA throughout the pancreas, which may cause exacerbation of the pancreatic inflammation. In humans with CP, a pancreatic duct obstruction may result from a stricture or a stone, which may theoretically prevent the feasibility of an effective chemical pancreatectomy. To account for this potential technical limitation in humans, assessment of the pancreatic morphology and ductal anatomy will be crucial before proceeding with intervention. Currently, several imaging modalities are used to visualize the pancreatic duct anatomy and potential sites of obstruction including the following: ERCP, which has a high 
sensitivity to detect even mild cases of CP (44) and magnetic resonance cholangiopancreatography (MRCP), which is sensitive in detecting moderate to severe pancreatitis (45). Additionally, when MRCP is combined with secretin hormone injection, a more comprehensive evaluation of the pancreatic duct can be obtained (46). According to the 2014 Cambridge Classification System, CP is classified into 4 stages based on imaging findings; only stage 4 is marked by significant intraductal filling defects and obstructions (47). Patients who have a severe duct obstruction can undergo endoscopic therapy to relieve the obstruction before proceeding with the chemical pancreatectomy. Specifically, pancreatic duct stones can be removed through a process of sphincterotomy, lithotripsy, stenting, and/or extraction (48-50). Also, pancreatic ductal strictures can be dilated with subsequent stent placement $(51,52)$. There is only a small number of patients in which ERCP interventions are not successful, with failure to decompress the obstructed pancreatic duct (53). Theoretically, these patients may not be candidates for a chemical pancreatotomy. However, the larger population of patients suffering from the symptoms of $\mathrm{CP}$ will likely benefit from this innovative therapy.

\section{Methods}

\section{Animals and animal manipulation}

Mice. Eight-week-old CD1 mice from both sexes were purchased from the Charles River Laboratories. The mice were maintained in an environment with a 12-hour light/ 12-hour dark cycle with the lights on from 7 am until 7 pm.

Pancreatic ductal infusion. The anesthetized mice underwent midline laparotomy. The common bile duct was exposed, clamped close to the liver, and cannulated by a blunt catheter across the duodenum. The catheter was clamped near its insertion at the ampulla, and 150 $\mu \mathrm{l}$ of the AcA was infused at a rate of $50 \mu \mathrm{l} / \mathrm{min}$ (54). All mice were maintained on elemental diet (Peptamen, 1.0CAL/55620A) mixed with mushed normal chow 1:1.

Ela ${ }^{\text {CrERT2 }}-R 26^{\text {DTR }}$ mice. To allow DTR expression selectively in acinar cells, we crossed R26-DTR mice (Jackson Laboratory) with Ela ${ }^{\text {CreERT2 }}$ mice. Six-week-old mice were first injected i.p. with tamoxifen (Sigma-Aldrich) for 5 days $(80 \mathrm{mg} / \mathrm{kg} / \mathrm{dose}$ ) to activate the Crerecombinase enzyme. Seven days after the last tamoxifen dose, to allow Cre-recombinase action, DT injections $(50 \mu \mathrm{g} / \mathrm{kg})$ were given for 3 consecutive days to ablate acinar cells.

NHPs. Experiments were performed on male Cynomolgus macaques who were 4 to 8 years old and purchased from Alpha Genesis Inc. NHPs weighed 3.5 to $6.5 \mathrm{~kg}$. Each NHP required a 30-day quarantine, followed by 1 to 2 weeks acclimatization. The NHPs were maintained in an environment with a 12-hour light/12-hour dark cycle with the lights on from 7 am to $7 \mathrm{pm}$. All animals had free access to water and received a diet consisting of biscuits, fruits, vegetables, and forage mix.

Pancreatic ductal infusion in NHP. Prior to surgery, we employed a jacket and tether system for 2 weeks to allow the NHP to acclimatize to the system. Before the surgery, the NHP was sedated using ketamine $(10 \mathrm{mg} / \mathrm{kg})$, then intubated and administered inhalational anesthesia with isoflurane. Following the placement of a tunneled central venous catheter into the right internal jugular vein, we performed a midline laparotomy and created a duodenotomy to identify the major papilla. We placed a temporary clamp on the common bile duct to prevent infusion into the liver and gall bladder. We then cannulated the common pancreatico-biliary channel using an umbilical catheter, and we held the catheter in place by a bulldog clamp to prevent backflow into the duodenum. Next, we infused $2 \%$ AcA, with a volume of $2 \mathrm{~mL} / \mathrm{kg}$, at a flow rate of $1 \mathrm{~mL} / \mathrm{min}$. After the laparotomy closure, the jacket and tether system were reapplied. NHPs received i.v. fluids, including dextrose $5 \%$ and normal saline overnight before resuming oral intake.

\section{Induction of $\mathrm{CP}$ in mice}

$\mathrm{CP}$ was induced by the cholecystokinin analogue cerulein (Bachem, 4030451). Cerulein was dissolved in normal saline and administered i.p. $(50 \mu \mathrm{g} / \mathrm{kg}$ ) every hour for 8 doses, twice weekly (Mondays and Thursdays) for two 8-week cycles (40). Simultaneously, we had a control group injected with vehicle (normal saline), and the i.p. injections were given as per the regimen described above. Subgroups of the mice were sacrificed at 4 and 8 weeks, and pancreata were harvested for histology to confirm the occurrence of CP.

\section{In vivo glucose homeostasis studies}

All the in vivo glucose homeostasis studies were performed on agematched CD1 female mice.

i.p. GTT. Overnight 16-hour-fasted mice were injected i.p. with 2 $\mathrm{g} / \mathrm{kg}$ glucose (Sigma-Aldrich). Blood glucose was measured from the tail vein at $0,15,30,60,90$, and 120 minutes after injection using a glucometer (Contour NEXT EZ).

i.v. GSIS. Overnight 16-hour-fasted mice were injected into the tail vein with $2 \mathrm{~g} / \mathrm{kg}$ glucose. During i.v. GTT, tail vein blood was collected at $0,2,5,10$, and 15 minutes for measuring serum insulin concentration using an ELISA kit (Alpco).

ITT. Six-hour-fasted mice were injected i.p. with 0.75 units $/ \mathrm{kg}$ regular insulin. Blood glucose was measured from the tail vein at 0,15 , 30,60 , and 90 minutes after insulin injection using the glucometer.

i.v. GTT in NHP. i.v. GTT in NHPs was done as described previously (55). After a 16-hour overnight fast, the NHP was sedated using ketamine $(10 \mathrm{mg} / \mathrm{kg}$ intramuscular) and kept sedated during the test. We then placed a peripheral i.v. catheter and obtained a fasting blood glucose using a glucometer (Contour NEXT EZ). Next, we administered dextrose $(0.5 \mathrm{~mL} / \mathrm{kg}$ of $50 \%$ dextrose $)$ i.v. and measured blood glucose from the heel pad at the following time points: 1, 3, 5, 7, 10, 15, and 30 minutes.

\section{Measurement of serum pancreatic enzymes and comprehensive metabolic profile}

Mice. We collected approximately $50 \mu \mathrm{L}$ of blood from the tail vein via the Microvette CB300 Capillary Blood Collection Tube. Serum pancreatic enzyme concentrations were measured using a mouse amylase ELISA kit (LifeSpan BioSciences) and mouse lipase ELISA kit (Aviva Systems Biology).

NHP. Blood was collected from the central line or peripherally from the saphenous vein. Pancreatic enzymes and comprehensive metabolic profile were measured using the Dimension Vista 500 chemistry analyzer (Siemens Medical Solutions USA Inc.).

\section{Pain assessment in mice}

Open-field activity. Open field activity was monitored by a trained professional. The total distance traveled and the duration of rearing were measured. Per previous studies, rodents thought to be in pain move 
shorter distances, and those with CP-associated abdominal pain have been shown to rear significantly less than control animals $(40,56)$.

Mechanical allodynia. An expert pain neurobiologist performed the abdominal von Frey assay on mice in order to directly test mechanical sensitivity. Mice were placed in wire mesh chambers on a standard von Frey table and acclimatized. Following adaptation of previously described protocols, von Frey filament no. 3.61 (equivalent to $0.4 \mathrm{~g}$ of force) was applied to the upper abdominal area overlying the pancreas (upper left) for approximately 2 seconds and withdrawal responses recorded (56-58). The monofilament was applied 10 times with a minimum of 30 seconds between applications. The number of positive withdrawal responses was converted into a percentage, with 10 positive responses corresponding to $100 \%$. The experimenter was blinded to mouse treatment groups for all behavioral tests.

\section{Tissue processing and histology}

All pancreas samples were fixed with $4 \%$ paraformaldehyde (PFA) for 24 hours at $4^{\circ} \mathrm{C}$. The tissues were then embedded into paraffin, and $5 \mu \mathrm{m}$ sections were cut. For IHC, antigen retrieval was performed (heat and/or acid buffer). Slides were incubated with primary antibodies (Supplemental Table 2) at $4^{\circ} \mathrm{C}$ overnight. The following day the slides were incubated with fluorescent-conjugated (FITC, CY3, CY5) secondary antibodies (Jackson ImmunoResearch Labs) for 1 hour at room temperature (RT). Nuclear staining and mounting were performed using Fluroshield with DAPI (Sigma-Aldrich). Histological assessments were made on paraffin-embedded $5 \mu \mathrm{m}$ sections of pancreata stained with H\&E.

\section{DRC harvesting and processing}

DRG from the T12 level were harvested and fixed in 4\% PFA. Following cryopreservation in $25 \%$ sucrose in $0.1 \mathrm{M}$ phosphate buffer at $4^{\circ} \mathrm{C}$, DRG were embedded in Tissue-Tek OCT compound (Fisher Scientific), sectioned $(14 \mu \mathrm{m})$, and mounted on Superfrost Plus slides (Fisher Scientific). Sections were stained for PGP9.5 and were photographed using LAS software and a Leica DM $4000 B$ microscope. DRG neurons in every fifth section were counted using Image J software (NIH).

\section{Whole-mount technique}

The whole-mount immunostaining was done as described previously (59). Briefly, the pancreas was minced into small pieces, $0.5 \mathrm{~mm} \times 0.5$ $\mathrm{mm}$, and then 100 pancreatic pieces were placed per well in a 96-well plate. Pancreatic pieces were washed on a rotator in PBS for $10 \mathrm{~min}-$ utes at RT $\times 3$ and then washed in methanol for 15 minutes at RT $\times 5$. Afterwards they were blocked with $10 \%$ normal donkey serum (NDS) for 45 minutes at RT; incubated with primary antibody in 1\% NDS at $4^{\circ} \mathrm{C}$ on a rotator overnight; washed with $0.1 \%$ PBST on a rotator at RT once an hour for 5 hours; incubated with secondary antibody in 1\% NDS at $4^{\circ} \mathrm{C}$ on rotator overnight; washed with PBST on rotator at RT for 10 minutes $\times 6$, and mounted on chamber slides with whole-mount media, after which coverslip was applied. Primary antibodies used were anti-insulin, and anti-PGP9.5 (Supplemental Table 2). DyLight 594-labeled Lycopersicon esculentum (Tomato) Lectin (t-lectin; 1:200; catalog DL-1177, Vector Laboratories; RRID: AB_2336416) was used as a marker of blood vessels as described previously (60).

\section{Transmission electron microscopy}

Ultrastructural changes of pancreatic acinar cells and islets were examined using transmission electron microscopy (TEM). After fixation
(2.5\% glutaraldehyde, 2\% PFA in 0.1 M sodium phosphate buffer), tissues were rinsed twice in $0.1 \mathrm{M}$ monosodium phosphate $\left(\mathrm{NaH}_{2} \mathrm{PO}_{4}\right)$ for 30 minutes and then placed in $1 \%$ osmium tetroxide in water for 1 hour. Tissues were rinsed twice in deionized water. The samples were then dehydrated in 50\% EtOH, 75\% EtOH, 95\% EtOH (30 minutes each), and finally in $100 \% \mathrm{EtOH}(20$ minutes $\times 2)$. Tissues were placed in propylene oxide ( 15 minutes $\times 2$ ) and were preinfiltrated in half resin/ half propylene oxide overnight. The next day, tissues were infiltrated in $100 \%$ resin for 5 hours. Then tissues were embedded with fresh resin and polymerized at $60^{\circ} \mathrm{C}$ overnight. The embedded tissues were sectioned with a Leica EM UC6 ultramicrotome at a thickness of $90 \mathrm{~nm}$ and collected on copper mesh grids. The sections were stained with $4 \%$ aqueous uranyl acetate for 30 minutes and 2 minutes in $0.2 \%$ lead citrate in $0.1 \mathrm{~N}$ sodium hydroxide $(\mathrm{NaOH})$. TEM imaging was performed on an FEI Talos L120C at $80 \mathrm{kV}$ using Thermo Scientific Ceta $16 \mathrm{MP}$ camera.

\section{$\beta$ Cell mass quantification}

Pancreata were harvested and fixed in $4 \%$ PFA for 24 hours at $4^{\circ} \mathrm{C}$, after which they underwent standard paraffinization. Sections at 50 $\mu \mathrm{m}$ intervals of the whole pancreas were stained with insulin and DAPI. The cross-sectional area of $\beta$ cells and cross-sectional area of total tissue were measured by Image J software. The $\beta$ cell mass of each pancreas was calculated by multiplying the average value of relative cross-sectional area of $\beta$ cells and the weight of the pancreas.

\section{Islet vasculature quantification}

Islet vasculature was calculated by dividing CD31-positive area by the sum of the insulin- and glucagon-positive areas. Then the mean percentage of 12 islets/mouse was calculated.

\section{Islet isolation}

Islet isolation was performed following a previously published protocol (61). The pancreatic duct was infused and subsequently digested with type $\mathrm{V}$ collagenase $(1.95 \mathrm{mg} / \mathrm{mL})$. In AcA-treated pancreata, collagenase was injected directly into the residual pancreas tissue due to the absence of ducts. Islets were separated from the exocrine tissue with a discontinuous Ficoll gradient and then washed with Hanks' Balanced Salt Solution (Gibco, Thermo Fisher Scientific) containing 20 mM HEPES buffer (Gibco, Thermo Fisher Scientific) and 0.2\% BSA (Sigma-Aldrich). Islets were then handpicked to eliminate any contamination from exocrine tissue.

\section{Acinar tissue isolation}

Acinar cell clumps were isolated as described previously (62). Mice were euthanized, and the harvested pancreas was rinsed in $6 \mathrm{~mL}$ of collagenase digestion buffer and was minced until the resulting solution appeared evenly dispersed. The minced product was transferred to a $125 \mathrm{~mL}$ Erlenmeyer plastic flask, and an additional $5 \mathrm{~mL}$ of collagenase digestion buffer was added. Afterwards, the Erlenmeyer plastic flask was placed into a $37^{\circ} \mathrm{C}$ water bath with shaking at $90 \mathrm{rpm}$ for 5 minutes. The suspension was then transferred to a conical tube, cells were allowed to settle, and the collagenase digestion buffer was exchanged. Next, the tube was shaken vigorously for 10 seconds to disperse the cells into smaller clusters, and tissues were allowed to settle down. Then media was exchanged with fresh BSA incubation buffer, and the incubation was repeated with shaking at $90 \mathrm{rpm}$ for 5 minutes. The digest was vigorously resuspended using 
a transfer pipette until the suspension appeared homogeneous. Next, the cell suspension was pipetted through a prewet nylon mesh into a conical flask, $10 \mathrm{~mL}$ of DMEM F-12 media was added, and the cells were allowed to settle for 2 to 3 minutes. We repeated the wash with the DMEM F-12 media twice, removed the supernatant with the final wash, and resuspended the cells into DMEM F-12 media. Clusters of acinar cells were hand-picked from the suspension, excluding islets, blood vessels, debris, and individual cells.

\section{Cell-death studies}

We performed in vitro cell-death studies on harvested islets or clusters of acinar cells. We applied 1\% AcA for the designated periods (1 and 5 minutes). The tissues were then washed with sterile PBS and trypsinized. Next, we added PI (Sigma-Aldrich, P4170) and incubated for 5 minutes. After washing in PBS, we quantified the number of dead cells using FACS.

\section{In vitro CSIS}

Islets were harvested from control and experimental mice and placed in RPMI media overnight. Following overnight culture, 30 islets per mouse were preincubated in a $2.8 \mathrm{mM}$ glucose solution for 30 minutes in a $37^{\circ} \mathrm{C}$ incubator. Next, islets were washed in Kreb's buffer twice and then transferred to a new well containing $2 \mathrm{~mL}$ fresh solution of $2.8 \mathrm{mM}$ glucose. Immediately $100 \mu \mathrm{L}$ of media was removed, labeled as time-point 0 , and stored. The islets were then incubated for $30 \mathrm{~min}$ utes in the $37^{\circ} \mathrm{C}$ incubator, and subsequently, we removed $100 \mu \mathrm{L}$ of media for time-point 1 . Finally, the islets were transferred into a well containing $2 \mathrm{~mL}$ of $20 \mathrm{mM}$ glucose solution for 30 minutes in the $37^{\circ} \mathrm{C}$ incubator, and $100 \mu \mathrm{L}$ of media was removed for time-point 2. Samples obtained were stored immediately at $-20^{\circ} \mathrm{C}$, and islets were then collected for protein quantification.

\section{RT-PCR}

DRGs at the level of T9-T12 were harvested, and RNA was isolated using the Quick-RNA kit (Zymo Research). RNA (0.5 $\mu \mathrm{g})$ was converted to cDNA using the iSCRIPT cDNA kit (Bio-Rad) and subjected to SYBR Green PCR amplification using a Bio-Rad CFX connect realtime system. The $\Delta \Delta \mathrm{CT}$ method was used to calculate relative fold changes of CGRP with respect to the standard reference gene GAPDH. CGRP is a neuropeptide released by DRG and is associated with nociception and neurogenic inflammation. Primer sequences are provided in Table Supplemental Table 3.

\section{Western blot}

Western blot was performed using protein isolated from the total pancreas, which was then separated on SDS-PAGE gels and subsequently transferred to the PVDF membrane. Membranes were then incubated with rabbit monoclonal anti- $\alpha$-amylase (Cell Signaling Technolo- gy, catalog 3796S), rabbit monoclonal anti-insulin (Abcam, catalog ab181547), and rabbit monoclonal anti- $\beta$-actin (Cell Signaling, catalog 4970S) antibodies. The secondary antibody was horseradish peroxidase-conjugated anti-rabbit (catalog 1705046, Bio-Rad). Band quantification was performed using ImageJ software.

\section{Study approval}

All mouse and NHP experiments were approved by the Animal Research and Care Committee at the Children's Hospital of Pittsburgh and the University of Pittsburgh Institutional Animal Care and Use Committee.

\section{Statistics}

AUC for GTT and in vivo GSIS were calculated by the trapezoidal method. All data are displayed as mean and SD. Comparisons between 2 groups were made using unpaired and paired, 2-tailed $t$ test as indicated. Comparison between multiple groups was made using 1- or 2-way ANOVA (with repeated measures where appropriate) followed by the Holm-Šidák test for multiple comparisons. $P \leq 0.05$ was considered as statistically significant, and statistical tests were conducted using GraphPad Prism, version 8.3.

\section{Author contributions}

MS and GKG designed the study, analyzed the data, and wrote the manuscript. GKG, MS, KS, RK, NM, PG, and JF performed the animal surgical procedures. MS, RK, KS, and AS performed histology staining and imaging. RK, AS, MS, KS, and YW performed the in vitro cell death studies and the Western blot studies. MS, KS, TZ, and KP performed and analyzed the glucose homeostasis data. JLS performed the pain assessment and DRG studies. All authors revised the article and approved the final version to be published. MS and GKG are the guarantors of this work and, as such, had full access to all the data in the study and take responsibility for the integrity of the data and the accuracy of the data analysis.

\section{Acknowledgments}

The authors thank Hulya Bayir and Elif Soysal for their assistance in performing the open field test, Aatur Singhi for his assistance in interpreting the histopathology data, and Maria Eulalia Rubio for her assistance in interpreting the electron microscopy data. We also thank Guy Agostinelli for his excellent technical assistance. We also acknowledge the support of the mouse facility and the histology core at the Children's Hospital of Pittsburgh Research Center. This work was partially supported by the NIH (R01DK120698 to GKG).

Address correspondence to: George K. Gittes, UPMC Children's Hospital of Pittsburgh, Pittsburgh, Pennsylvania 15224, USA. Phone: 412.692.7291; Email: George.Gittes@chp.edu.

\footnotetext{
1. Machicado JD, et al. Period prevalence of chronic pancreatitis diagnosis from 2001-2013 in the commercially insured population of the United States. Pancreatology. 2019; 19(6):813-818.

2. Lankisch PG, et al. Epidemiology of pancreatic diseases in Lüneburg County. A study in a defined German population. Pancreatology. 2002;2(5):469-477.
}

\footnotetext{
3. Levy P, et al. Estimation of the prevalence and incidence of chronic pancreatitis and its complications. Gastroenterol Clin Biol. 2006;30(6-7):838-844

4. Hirota M, et al. The sixth nationwide epidemiological survey of chronic pancreatitis in Japan. Pancreatology. 2012;12(2):79-84.

5 . Yadav D, et al. Incidence, prevalence, and survival
}

of chronic pancreatitis: a population-based study. Am J Gastroenterol. 2011;106(12):2192-2199.

6. Granados A, et al. Cystic fibrosis related diabetes: Pathophysiology, screening and diagnosis. J Cyst Fibros. 2019;18(Suppl 2):S3-S9.

7. Fasanella KE, et al. Pain in chronic pancreatitis and pancreatic cancer. Gastroenterol Clin North Am. 2007;36(2):335-364. 
8. Majumder S, Chari ST. Chronic pancreatitis. Lancet. 2016;387(10031):1957-1966.

9. Kirkegard J, et al. Chronic pancreatitis and pancreatic cancer risk: a systematic review and meta-analysis. Am J Gastroenterol. 2017;112(9):1366-1372.

10. Siegel RL, et al. Cancer statistics, 2019. CA Cancer J Clin. 2019;69(1):7-34.

11. Ryan DP, et al. Pancreatic adenocarcinoma. N Engl JMed. 2014;371(22):2140-2141.

12. Hart PA, Conwell DL. Chronic pancreatitis: managing a difficult disease. Am J Gastroenterol. 2019;115(1):49-55.

13. Malka D, et al. Risk factors for diabetes mellitus in chronic pancreatitis. Gastroenterology. 2000;119(5):1324-1332.

14. Cui Y, Andersen DK. Pancreatogenic diabetes: special considerations for management. Pancreatology. 2011;11(3):279-294.

15. Ewald N, Bretzel RG. Diabetes mellitus secondary to pancreatic diseases (Type $3 \mathrm{c}$ ) - are we neglecting an important disease? Eur J Intern Med. 2013;24(3):203-206.

16. Benkovic V, et al. The economic burden of disease-related undernutrition in selected chronic diseases. Clin Nutr. 2014;33(4):689-693.

17. Moran A, et al. Cystic fibrosis-related diabetes: current trends in prevalence, incidence, and mortality. Diabetes Care. 2009;32(9):1626-1631.

18. Bellin MD, et al. Total pancreatectomy with islet autotransplantation improves quality of life in patients with refractory recurrent acute pancreatitis. Clin Gastroenterol Hepatol. 2016;14(9):1317-1323.

19. Altinel D, et al. Lipomatous pseudohypertrophy of the pancreas: a clinicopathologically distinct entity. Pancreas. 2010;39(3):392-397.

20. Olsen TS. Lipomatosis of the pancreas in autopsy material and its relation to age and overweight. Acta Pathol Microbiol Scand A. 1978;86A(5):367-373.

21. Soyer P, et al. Cystic fibrosis in adolescents and adults: fatty replacement of the pancreas-CT evaluation and functional correlation. Radiology. 1999;210(3):611-615.

22. Tariq $\mathrm{H}$, et al. Non-alcoholic fatty pancreatic disease: a review of literature. Gastroenterology Res. 2016;9(6):87-91.

23. Hogan MF, Hull RL. The islet endothelial cell: a novel contributor to beta cell secretory dysfunction in diabetes. Diabetologia. 2017;60(6):952-959.

24. Lerch MM, Gorelick FS. Models of acute and chronic pancreatitis. Gastroenterology. 2013;144(6):1180-1193.

25. Criscimanna A, et al. Duct cells contribute to regeneration of endocrine and acinar cells following pancreatic damage in adult mice. Gastroenterology. 2011;141(4):1451-1462.

26. Stram M, et al. Chronic pancreatitis. Surg Pathol Clin. 2016;9(4):643-659.

27. Moreno-Gonzalez G, et al. Necroptosis: a novel cell death modality and its potential relevance for critical care medicine. Am J Respir Crit Care Med. 2016;194(4):415-428.

28. Vanden Berghe T, et al. Determination of apop- totic and necrotic cell death in vitro and in vivo. Methods. 2013;61(2):117-129.

29. Lopez-Alonso B, et al. Histopathological and ultrastructural changes after electroporation in pig liver using parallel-plate electrodes and high-performance generator. Sci Rep. 2019;9(1):2647.

30. Li WC, et al. Activation of pancreatic-duct-derived progenitor cells during pancreas regeneration in adult rats. JCell Sci. 2010;123(Pt 16):2792-2802.

31. Rankin MM, et al. $\beta$-Cells are not generated in pancreatic duct ligation-induced injury in adult mice. Diabetes. 2013;62(5):1634-1645.

32. Korpos E, et al. The peri-islet basement membrane, a barrier to infiltrating leukocytes in type 1 diabetes in mouse and human. Diabetes. 2013;62(2):531-542.

33. Reid C, Narayana B. Studies in blood diastase. Factors which cause variations in the amount of diastase in the blood. Experimental Physiology. 1930;20(4):305-311.

34. Singh $\mathrm{H}$, et al. Amylase and lipase secretion in the hepatic and intestinal lymph. II. Progressive changes in enzyme levels following pancreatectomy. Arch Surg. 1969;99(1):80-82.

35. Nardi GL. Metabolic studies following total pancreatectomy for retroperitoneal leiomyosarcoma. N Engl JMed.1952;247(15):548-550.

36. Janowitz HD, Dreiling DA. The plasma amylase. Source, regulation and diagnostic significance. Am J Med. 1959;27:924-935.

37. Dreiling DA, et al. Relationship between blood amylase and factors affecting carbohydrate metabolism. II. The influence of ACTH, hydrocortisone, liver disease and pancreatectomy. $A m$ J Dig Dis. 1959;4:731-736.

38. Wlaz J, et al. Pancreatic and gastric heterotopy in the gastrointestinal tract. Postepy Hig Med Dosw (Online). 2014;68:1069-1075.

39. Anaparthy R, Pasricha PJ. Pain and chronic pancreatitis: is it the plumbing or the wiring? Curr Gastroenterol Rep. 2008;10(2):101-106.

40. Schwartz ES, et al. TRPV1 and TRPA1 antagonists prevent the transition of acute to chronic inflammation and pain in chronic pancreatitis. JNeurosci. 2013;33(13):5603-5611.

41. Olesen SS, et al. Pain-associated adaptive cortical reorganisation in chronic pancreatitis. Pancreatology. 2010;10(6):742-751.

42. Bouwense SA, et al. Systematic mechanismorientated approach to chronic pancreatitis pain. World J Gastroenterol. 2015;21(1):47-59.

43. Morgan K, et al. Pain control and quality of life after pancreatectomy with islet autotransplantation for chronic pancreatitis. J Gastrointest Surg. 2012;16(1):129-133.

44. [No authors listed]. NIH state-of-the-science statement on endoscopic retrograde cholangiopancreatography (ERCP) for diagnosis therapy. NIH Consens State Sci Statements. 2002;19(1):1-26.

45. Tirkes T. Chronic pancreatitis: what the clinician wants to know from mr imaging. Magn Reson Imaging Clin N Am. 2018;26(3):451-461.

46. Sherman S, et al. Administration of secretin (RG1068) increases the sensitivity of detection of duct abnormalities by magnetic resonance cholangiopancreatography in patients with pancreatitis. Gastroenterology. 2014;147(3):646-654.e2.

47. Conwell DL, et al. American Pancreatic Association practice guidelines in chronic pancreatitis: evidence-based report on diagnostic guidelines. Pancreas. 2014;43(8):1143-1162.

48. Smits ME, et al. Endoscopic treatment of pancreatic stones in patients with chronic pancreatitis. Gastrointest Endosc. 1996;43(6):556-560.

49. Kozarek RA, et al. Endoscopic pancreatic duct sphincterotomy: indications, technique, and analysis of results. Gastrointest Endosc. 1994;40(5):592-598.

50. Ueno N, et al. Treatment of pancreatic duct stones with the use of endoscopic balloon sphincter dilation. Gastrointest Endosc. 1998;47(3):309-310.

51. Carr-Locke DL. Endoscopic therapy of chronic pancreatitis. Gastrointest Endosc. 1999; 49(3 Pt 2):S77-S80.

52. Ashby K, Lo SK. The role of pancreatic stenting in obstructive ductal disorders other than pancreas divisum. Gastrointest Endosc. 1995;42(4):306-311.

53. Seicean A, Vultur S. Endoscopic therapy in chronic pancreatitis: current perspectives. Clin Exp Gastroenterol. 2015;8:1-11.

54. Xiao $X$, et al. Pancreatic cell tracing, lineage tagging and targeted genetic manipulations in multiple cell types using pancreatic ductal infusion of adeno-associated viral vectors and/or celltagging dyes. Nat Protoc. 2014;9(12):2719-2724.

55. Xiao YF, et al. Xylazine-induced reduction of tissue sensitivity to insulin leads to acute hyperglycemia in diabetic and normoglycemic monkeys. BMC Anesthesiol. 2013;13(1):33.

56. Saloman JL, et al. Animal models: challenges and opportunities to determine optimal experimental models of pancreatitis and pancreatic cancer. Pancreas. 2019;48(6):759-779.

57. Saloman JL, et al. Gi-DREADD expression in peripheral nerves produces ligand-dependent analgesia, as well as ligand-independent functional changes in sensory neurons. J Neurosci. 2016;36(42):10769-10781.

58. Samineni VK, et al. Optogenetic silencing of nociceptive primary afferents reduces evoked and ongoing bladder pain. Sci Rep. 2017;7(1):15865

59. El-Gohary Y, et al. Whole-mount imaging demonstrates hypervascularity of the pancreatic ducts and other pancreatic structures. Anat Rec (Hoboken). 2012;295(3):465-473.

60. Kalyan-Masih P, et al. Western high-fat diet consumption during adolescence increases susceptibility to traumatic stress while selectively disrupting hippocampal and ventricular volumes. eNeuro. 2016;3(5):ENEURO.0125-16.2016.

61. Bertera S, et al. Increased yield and improved transplantation outcome of mouse islets with bovine serum albumin. J Transplant. 2012;2012:856386.

62. Orabi AI, et al. Preparation of pancreatic acinar cells for the purpose of calcium imaging, cell injury measurements, and adenoviral infection. JVis Exp. 2013;(77):e50391. 